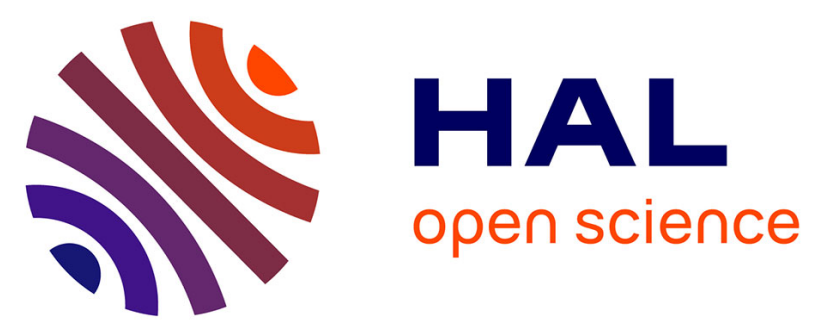

\title{
Zonal Detached Eddy Simulation of a simplified nose landing-gear for flow and noise predictions using an unstructured Navier-Stokes solver
}

Fernando de La Puente Cerezo, Laurent Sanders, François Vuillot, Philippe Druault, Eric Manoha

\section{To cite this version:}

Fernando de La Puente Cerezo, Laurent Sanders, François Vuillot, Philippe Druault, Eric Manoha. Zonal Detached Eddy Simulation of a simplified nose landing-gear for flow and noise predictions using an unstructured Navier-Stokes solver. Journal of Sound and Vibration, 2017, 405, pp.86 - 111. 10.1016/j.jsv.2017.05.046 . hal-01396210

\author{
HAL Id: hal-01396210 \\ https://hal.science/hal-01396210
}

Submitted on 14 Nov 2016

HAL is a multi-disciplinary open access archive for the deposit and dissemination of scientific research documents, whether they are published or not. The documents may come from teaching and research institutions in France or abroad, or from public or private research centers.
L'archive ouverte pluridisciplinaire HAL, est destinée au dépôt et à la diffusion de documents scientifiques de niveau recherche, publiés ou non, émanant des établissements d'enseignement et de recherche français ou étrangers, des laboratoires publics ou privés. 


\title{
Zonal Detached Eddy Simulation of a simplified nose landing-gear for flow and noise predictions using an unstructured Navier-Stokes solver
}

\author{
Fernando de la Puente Cerezo ${ }^{\mathrm{a}, *}$, Laurent Sanders $^{\mathrm{a}}$, François Vuillot $^{\mathrm{a}}$, Philippe Druault $^{\mathrm{b}}$, Eric Manoha $^{\mathrm{a}}$ \\ a ONERA - The French Aerospace Lab \\ F-92322 Châtillon, France \\ ${ }^{b}$ Université Pierre et Marie Curie - Paris VI \\ F-75005 Paris, France
}

\begin{abstract}
A Zonal Detached Eddy Simulation (ZDES) has been performed on the simplified LAGOON nose landing gear geometry using a Navier-Stokes solver on a fully unstructured grid. The attached boundary layers have been finely resolved using $Y^{+}$values in the order of unity, while the high curvature zones have been intensively meshed in order to accurately solving adverse pressure gradients present in these regions. The mean and fluctuating flow fields have been compared with the experimental results, proving that both the mean flow field and the spectral content recorded at the wall are accurately reproduced. Following these comparisons, a detailed analysis of the topology of the flow has been carried out through the analysis of the skin friction coefficient and friction lines, coupled with three dimensional visualizations of the landing gear wake. The far-field acoustics, computed through the Ffowcs-Williams and Hawkings (FW-H) equation from the computed pressure on the landing gear skin, has been compared with the experimental results, obtaining a very good agreement for the different microphones and directions. Finally, the CFD methodology presented in this study proves to be a moderate cost approach, enabling an accurate flow and noise prediction for bluff bodies such as landing gears.
\end{abstract}

Keywords: Landing gear, ZDES, Unstructured grid, Acoustics, CFD

\section{Introduction}

Because of the growth of cities, the airports that once were far away from inhabited areas are now being surrounded by residential areas. This, coupled with the exponential growth of passengers and cargo air transportation, has generated an increase of the population noise exposure.

During the last decades, the main acoustic sources of an airliner have been drastically reduced. For instance, jet noise was strongly reduced thanks to the use of high by-pass ratio jet engines and of reduction devices, such as chevrons. As a consequence, other noise sources started to emerge. This is the case for the airframe noise which is usually decomposed into high-lift devices noise (flaps and slats) and landing gear noise, both including particular contributions such as cavity noise and interaction noise.

During the takeoff phase of an airliner, the engines are set to maximum power, while the flaps and slats are partially extended. The landing gears are rapidly retracted in order to gain speed. On the other hand, during the approach phase, the engines are almost set to idle while the flaps and slats are extended at maximum position and the landing gears are deployed during a significant larger amount of time when compared to takeoff. This leads to a distribution of noise sources completely different from that of the takeoff phase, with airframe noise becoming dominant. This is illustrated in Figure 1, taken from Piet et al. [1], where important contributions of airframe noise to the total noise can be distinguished.

\footnotetext{
${ }^{*}$ Corresponding author

Email address: fernando.de_la_puente@onera.fr (Fernando de la Puente Cerezo)
} 


\begin{tabular}{|c|c|c|c|}
\hline \multicolumn{2}{|c|}{ Nomenclature } & $d_{w}$ & Wall distance \\
\hline \multirow[t]{2}{*}{$\Delta \omega$} & \multirow{2}{*}{$\begin{array}{l}\text { Subgrid length corrected with the local flow } \\
\text { vorticity }\end{array}$} & \multicolumn{2}{|c|}{$f_{\text {Cut-off }}$ Cut-off frequency } \\
\hline & & $f_{d 0}$ & ZDES subgrid length scale constant \\
\hline$\Delta f$ & Frequency resolution & $f_{D D E S}$ & DDES blending function \\
\hline$\Delta \max$ & Subgrid length scale based on the cell size & $L_{i i}$ & Integral length scale \\
\hline$\Delta t$ & Time step & $r_{d}$ & DES parameter \\
\hline$\Delta v o l$ & $\begin{array}{l}\text { Subgrid length scale based on the cell vol- } \\
\text { ume }\end{array}$ & $R_{i i}$ & Correlation function \\
\hline$\Delta y_{1}$ & First prism layer height & $t_{D}$ & Convective time $t_{D}=\frac{D}{U_{\infty}}$ \\
\hline$\Delta$ & Cell size & $U_{i j}$ & Velocity gradient \\
\hline$\infty$ & Infinite flow condition & $Y^{+}$ & Dimensionless wall distance \\
\hline$\kappa$ & Von-Kármán constant & $\mathrm{Cp}$ & Pressure coefficient $C p=\frac{P-P_{\infty}}{\frac{1}{2} \rho_{\infty} U_{\infty}^{2}}$ \\
\hline$v$ & Fluid kinematic viscosity & $\mathrm{Cx}$ & Drag coefficient $C x=\frac{F_{x}}{\frac{1}{2} \rho_{\infty} U_{\infty}^{2}}$ \\
\hline$v_{t}$ & Eddy viscosity & $\mathrm{D}$ & Wheel diameter $\mathrm{D}=300 \mathrm{~mm}$ \\
\hline$\rho$ & Fluid density & $\mathrm{H}$ & Wheel cavity depth $\mathrm{H}=37 \mathrm{~mm}$ \\
\hline & Turbulent Prandtl number $\sigma=\frac{2}{3}$ & $\mathrm{~L}$ & Inter-wheel distance $\mathrm{L}=198 \mathrm{~mm}$ \\
\hline$\theta, \alpha, \beta$ & Angular coordinates & M & Flow Mach number \\
\hline$\tilde{v}$ & Spalart-Allmaras model transported scalar & $P$ & Fluid pressure \\
\hline & $\begin{array}{l}\text { ZDES modifled wall distance } \\
\text { Snalart-Allmaras model modified vorticity }\end{array}$ & RMS & Root-Mean-Square \\
\hline & $\begin{array}{l}\text { magnitude } \\
\text { mas }\end{array}$ & $\mathrm{T}$ & Fluid temperature \\
\hline$c_{b 1}, c_{b 2}$ & $c_{w 1}$ Spalart-Allmaras model constants & $\mathrm{t}$ & Solution time \\
\hline$C_{D E S}$ & DES constant $C_{D E S}=0.65$ & $\mathrm{U}, \mathrm{V}, \mathrm{W}$ & Cartesian velocity components \\
\hline$D_{\text {Cavity }}$ & Wheel cavity diameter $D_{\text {Cavity }}=162 \mathrm{~mm}$ & $\mathrm{X}, \mathrm{Y}, \mathrm{Z}$ & Cartesian coordinates \\
\hline
\end{tabular}

For the reasons stated above, large efforts are currently being made by the research laboratories, in close relation with the industry, for significantly reducing these "new" sources. In order to do so, highly accurate numerical simulations of the noise emitted by each of the components of the airframe i.e. the isolated landing gears, flaps and slats 20 are needed. Secondly, the methodologies developed have to be flexible enough in order to deal with various configurations of growing complexity. Finally, these methodologies must be affordable, in terms of cost and restitution time, in order to be integrated in the design phase, in such a way that, the impact of any design modification on the emitted noise can be assessed, prior to the landing gear manufacture.

In order to predict airframe noise, and especially landing gear noise, as is the objective of the present article, 25 several challenges have to be addressed. The first one relies on the complexity of the geometries used. Structured grids have been historically widely used for flow simulation. Nevertheless, the mesh generation process on complex geometries becomes tedious, and sometimes can led to low quality cells, if attached boundary layers are to be finely solved. A successful application of structured multi-block grids to landing gear noise predictions is found in Liu et al. [2] that used these family of grids on the LAGOON geometry (see \$2) coupled with high-order numerical schemes. so In order to overcome some of the difficulties and constraints of the structured grid generation, the Chimera technique can be used. This technique relies on the use of a series of overset grid blocks and has been applied by P. Spalart $e t$ al. [3], allowing to successfully deal with relatively complex geometries as the four-wheel rudimentary landing gear. 


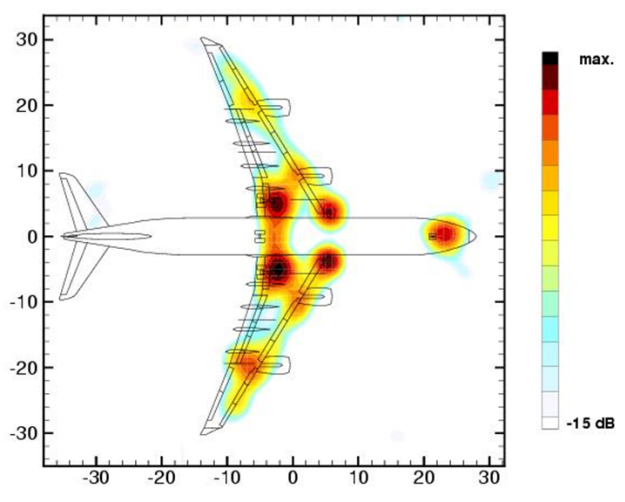

Figure 1: Beamforming measurements of an Airbus A-340 approaching with the engines set to idle condition for a frequency of 4 kHz (extracted from Piet et al. [1])

A drawback of this technique is found at the junctions between different overset blocks, as spurious acoustic waves can be generated polluting the numerical solution over the whole computational domain. Moreover, the growing 5 complexity of the landing gears imposes a multiplication of the overset blocks, hence, this technique is better adapted for simple geometries. Another meshing technique consists in using unstructured grids, allowing an almost automatic mesh generation process, or at least, a much faster one, when compared to structured grids. Thanks to the use of tetrahedral elements, unstructured grids are easily adapted to any kind of geometry. This family of grids has been applied to a wide range of configurations e.g. on the four-wheel rudimentary landing gear by Langtry et al. [4]. Giret

40 et al. [5] applied a full tetrahedra grid to the LAGOON nose landing gear and $4^{\text {th }}$ order numerical schemes. The hybrid unstructured approach is the one retained for the present work that uses a combination of prisms, allowing to impose a desired cell anisotropy in the attached boundary layer regions, and tetrahedra in other regions, where the isotropy of the cells is beneficial, for instance in the wake of the landing gear.

The second major challenge of landing gear noise prediction is related to the complexity of the flow to be solved.

45 Landing gear flow contains a mix of attached boundary layers with fully turbulent detached flow, interactions between different geometrical components and massive flow detachments that are very sensitive to adverse pressure gradients. For these reasons, the choice of the turbulence model is not unique, and in general relies on the use of the Large Eddy Simulation (LES) or hybrid RANS-LES models derived from the Detached Eddy Simulation (DES), such as the Delayed Detached Eddy Simulation (DDES) proposed by P. Spalart et al. [6] or the Zonal Detached Eddy Simulation 50 (ZDES) proposed by Deck et al. [7]. These methods are based on solving the Navier-Stokes equations in the conventional CFD manner. Recently, some landing gear computations have been performed using the Lattice Boltzmann Method (LBM), which no longer uses the Navier-Stokes equations, but instead a stochastic modelization of the flow dynamics through the Boltzmann equation. This method has proved to be very efficient not only because of its inherent computational efficiency, but also because it makes use of automatic mesh generation procedures, based on cubic 55 voxels intersecting the landing gear geometry with non conformal matching between different grid resolution zones. It was used for landing gear noise predictions by Casalino et al. [8] and Murayama et al. [9] providing successful results. The main drawback of the LBM is its relatively limited cumulated experience by the scientific community, due to its recent development. Secondly, it requires advanced wall functions in order to capture the physics inside attached boundary layers, limiting its overall applicability. Finally, the application LBM is currently limited to low 60 Mach number flows.

The present article deals with predicting the noise emitted by the LAGOON simplified landing gear using hybrid unstructured grid, with a Zonal Detached Eddy Simulation (ZDES) turbulence model and the Navier-Stokes solver of the ONERA in-house CEDRE code. The LAGOON case, due to its relative simplicity, will be used to develop and validate a methodology to accurately predict landing gear noise at the lowest computational cost. In other words, it serves as a necessary validation milestone prior to the application on real life industrial configurations. The next Section will present the LAGOON case in detail. Then, in $\$ 3.1$, a detailed description of the grid construction is provided, while in $\S 3.2$ the numerical parameters used for the flow simulation are presented. Then $\S 4$ will present 
and discuss the main aerodynamic results, followed by the acoustic results detailed in $\S 5$. Finally $\S 6$ will present the conclusions of this work.

70

\section{The LAGOON project}

Founded by AIRBUS, ONERA, DLR and University of Southampton, the LAGOON (LAnding Gear nOise database for CAA validatiON) project aimed at providing an extensive database of flow and noise measurements for the development of new CFD/CAA strategies for landing gear noise predictions. The geometry used is based on a highly simplified 2:5 scaled AIRBUS single aisle aircraft nose landing gear. It was extensively tested both for aerodynamics and aeroacoustics measurements at ONERA's F2 and CEPRA19 wind tunnels, as can be seen in Figure 2. More details about the experimental campaigns in F2 and CEPRA19 and some of the results can be found in [10] and [11] respectively.
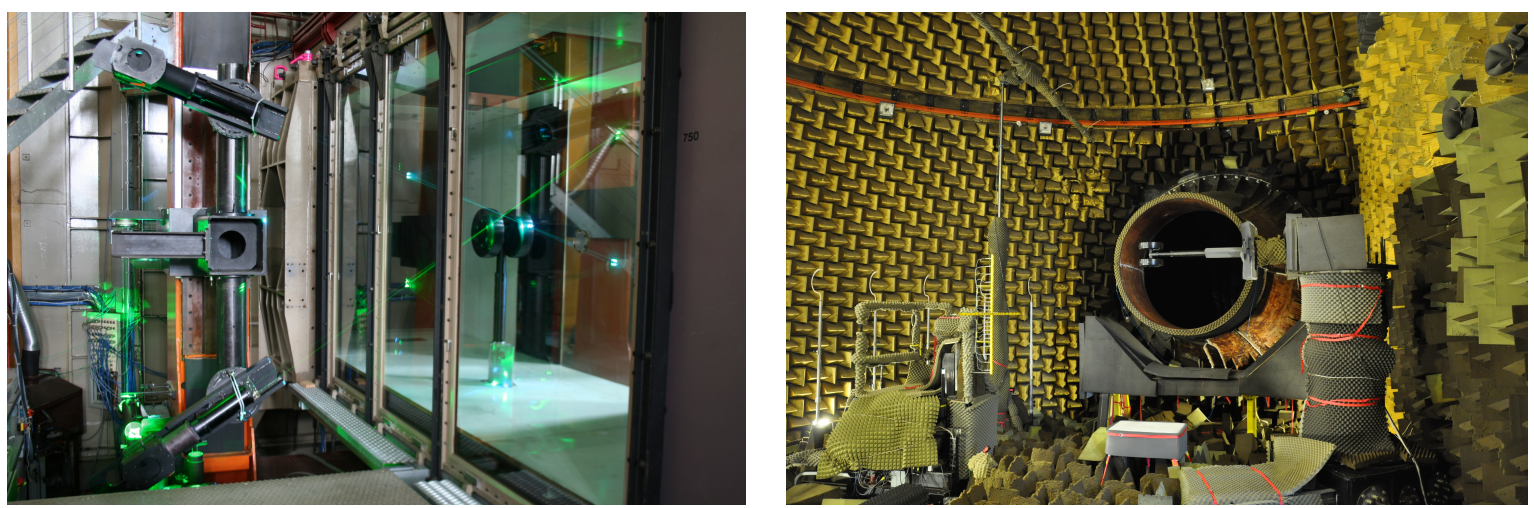

Figure 2: 3D LDV measurements on the LAGOON landing gear at the F2 wind tunnel (left) and installation of the model in the aeroacoustic wind tunnel CEPRA19 (right)

The experimental campaigns covered steady and unsteady pressure measurements in the two wind tunnels, mean off-body flow measurements through bi-dimensional Particle Image Velocimetry (PIV) and unsteady two and three dimensional Laser Doppler Velocimetry (LDV) and hotwire measurements, allowing for a detailed insight of the flow topology and the characterization of the turbulent field behind the landing gear through the combined use of LDV and hot-wire anemometry. Finally, during the test performed in ONERA's aeroacoustic wind tunnel CEPRA19, the noise emitted by this landing gear was also measured at different locations in the flyover and sideline directions. Some beamforming analyses were also performed, especially for characterising the resonant frequencies of 1 and $1.5 \mathrm{kHz}$ observed, thanks to the installation in the wind tunnel of a set of dedicated antennas, as presented in references [10] and [11].

In the framework of this project, several configurations of growing geometrical complexity were tested at different velocities. For the present study the simplest configuration (Configuration \# 1, see Figure 3 (a)) has been retained with an incoming flow Mach number of 0.23 .

As shown in Figure 3 (b), this landing gear has an inter-wheel distance (L) of $198 \mathrm{~mm}$ and a wheel diameter (D) of $300 \mathrm{~mm}$. The Reynolds number based on the wheel diameter is close to $1.54 \mathrm{e}+06$. Despite this high Reynolds number value, the boundary layers developing over the tires, the leg and the wheel axle, were tripped, in order to fix the location of the boundary layer transition to turbulence. This point was intended to simplify the computational needs on numerical computations and increasing the repetitiveness of the experiments. A detail of this treatment is shown in Figure 3 (c), where the zigzag stripes applied on the tire, and the small dots on the leg and wheel axle, are visible. 


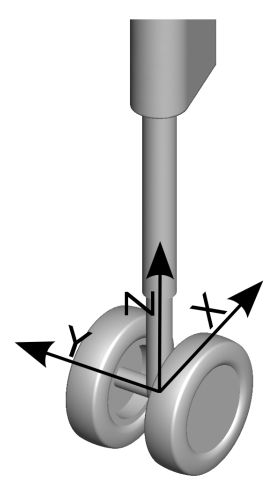

(a)

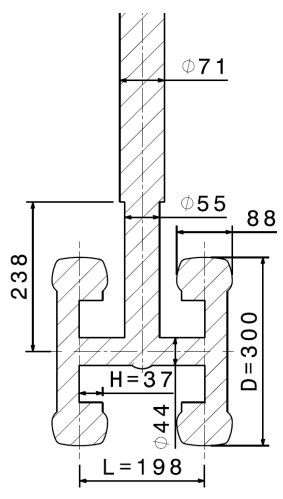

(b)

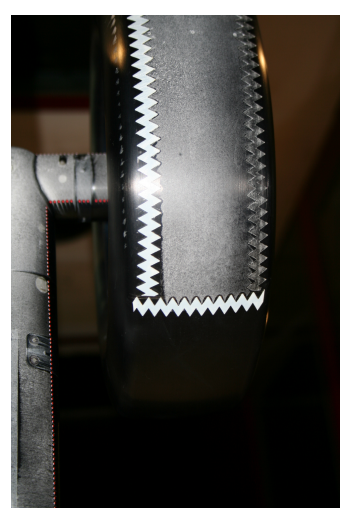

(c)

Figure 3: LAGOON geometry and retained axis system (a), main dimensions (b) and experimental boundary layer triggering with acenaphten visualization (c)

\section{Computational setup}

In the present section, the details of the performed numerical simulation are presented, covering the grid construction process, the different numerical parameters used in the CEDRE code, and the computational resources needed for the computation.

\subsection{Mesh generation}

The present computation is based on a previous computation performed with the CEDRE code on the same geometry, presented in reference [12]. A second hybrid grid is constructed based on the previous one, re-arranging the elements of the grid in order to obtain a refined grid with the same mesh metrics, hence the computational cost is expected to be comparable.

The fluid domain size is defined for preventing the propagation of any acoustic reflection from the boundaries back to the model. The dimensions of the bounding box retained are 40D in the streamwise direction, 24D in the crosswise direction and $18 \mathrm{D}$ in the vertical direction.

As presented in Table 1, a 62 million element hybrid grid is generated, containing 19 million prisms, for resolving the attached boundary layers, with $Y^{+}$values in the order of unity, as shown in Figure 4. This is achieved by using a stack of 22 prism layers, with a first layer height $\left(\Delta y_{1}\right)$ of $D / \Delta y_{1}=2 \mathrm{e}+04$. It is important to mention that the bottom of both wheel cavities is not treated with prisms, as the flow is completely detached at these locations. Hence, a classical logarithmic law of the wall is applied on the tetrahedra used in this region, with $Y^{+}$values around 30 , well in the region of validity of such kind of laws.

\begin{tabular}{|c|c|}
\hline Element count $(1 \mathrm{e}+06)$ & 61.8 \\
\hline Node count $(1 \mathrm{e}+06)$ & 17.2 \\
\hline Tetrahedra $(1 \mathrm{e}+06)$ & 42.4 \\
\hline Prisms $(1 \mathrm{e}+06)$ & 19.3 \\
\hline Pyramids $(1 \mathrm{e}+03)$ & 25.0 \\
\hline Hexahedra $(1 \mathrm{e}+03)$ & 30.0 \\
\hline
\end{tabular}

Table 1: Mesh cell count 

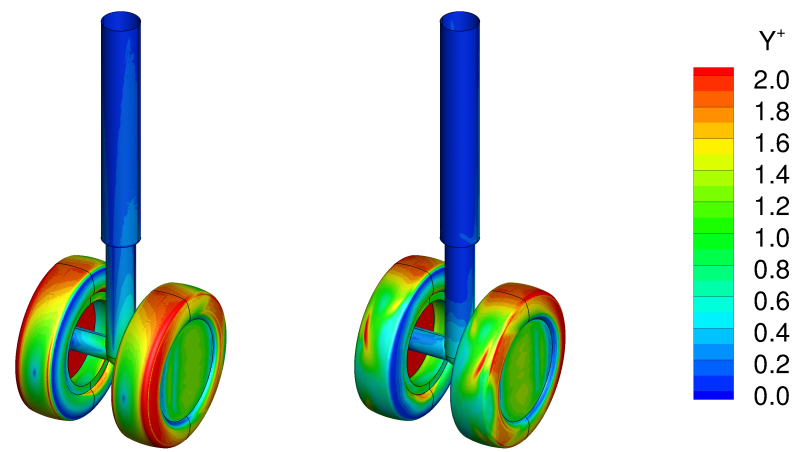

Figure 4: Time averaged $Y^{+}$on the upstream (left) and downstream (right) part of the landing gear the tire (see Figure 5 (a)), which are found to be of major importance for the flow development, as the boundary layer detaches over them due to the presence of adverse pressure gradients. The cell size $(\Delta)$ used at the skin, ranges from $D / \Delta=240$ for the coarsest zones up to $D / \Delta=400$ for the finest zones.

Finally, a set of volume refinement zones is used around the landing gear, as can be seen in Figure 5 (b). The first one, placed between the two wheel cavities, aims at correctly propagating the turbulent structures which are shed by the detached boundary layer on the upstream part of the tire through the wheel axle down to the downstream part of the tire. The size of the tetrahedra $(\Delta)$ used in this refinement zone is kept constant to $D / \Delta=187.5$. Furthermore, based on a 20 points per wavelength acoustic criterion, this cell size should ensure an accurate acoustic propagation of waves upto $13 \mathrm{kHz}$. The second volume refinement focuses on the wheel wake and its vicinity, with cell sizes ranging from $D / \Delta=187.5$ at the wheels axle down to $D / \Delta=120$ at $X / D=2.5$, downstream of the landing gear. Based on the same criterion as for the previous refinement, the chosen cell size should lead to $f_{\text {cut-off }} \approx 8 \mathrm{kHz}$ (for pure convective hydrodynamic structures, the cut-off frequency will be lower, by a ratio equal to the Mach number of the flow). As visible on Figure 5 (b), the shape of this second refinement is a simple cylinder. The size of the tetrahedra outside of these refinement zones is left to gradually increase, down to the boundaries, following a geometric law.

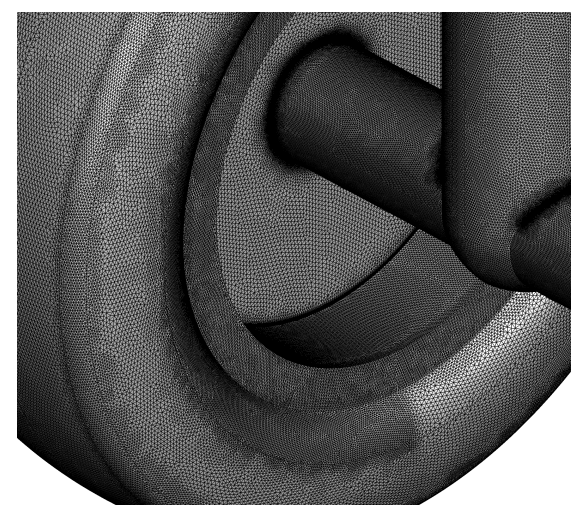

(a)

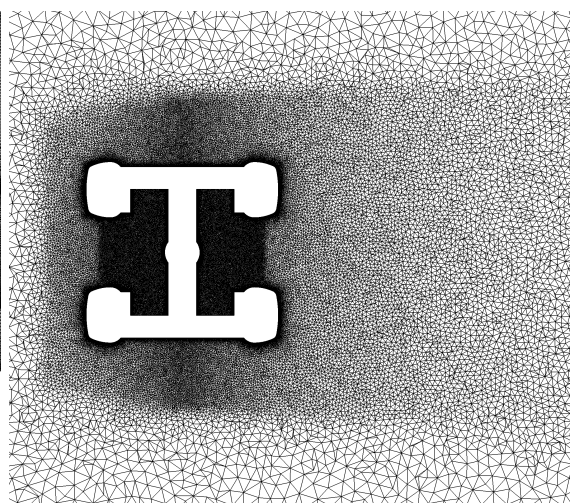

(b)

Figure 5: Detail of the surface mesh in the vicinity of the tires and wheel axle (a) and section of the volume mesh extracted at $Z / D=0$, showing the different volume mesh refinements (b) 


\subsection{Numerical setup}

As previously mentioned, ONERA's in-house CEDRE code [13] (Calcul d'Ecoulements Diphasiques et Réactifs pour l'Energétique) is used. This solver is a multi-physics, multi-species, cell centred, unstructured, finite volume, Navier-Stokes equations solver, originally developed for combustion and propulsion simulations. Due to the use of a generalized polyhedra formulation, it is well adapted to deal with highly complex geometries, as it is the case of 35 landing gears.

The simulation was initialized with 3.6 seconds of Unsteady Reynolds Averaged Navier-Stokes (URANS) computation, which represents $T / T_{D}=935$, where $T_{D}$ stands for the convective time based on the wheel diameter and the free stream velocity. This first phase gives a converged mean flow field to serve as initial conditions for the second part of the computation using the Zonal Detached Eddy Simulation (ZDES) that will provide the data for the flow and 40 acoustic analyses.

The ZDES, as proposed by Deck [7], is a hybrid RANS-LES turbulence model that combines the precision and reduced cost of RANS models for solving attached boundary layers with the accuracy of the LES for solving fully turbulent detached flows. In the present computation, the second mode of this turbulence model is retained, as it automatically protects the boundary layer in RANS while shifting rapidly into LES when the flow detaches. This fast transition is ensured by the blending function $f_{D D E S}$ that was defined by Spalart [6] for the Detached Eddy Simulation (DDES) in the shape of a hyperbolic tangent function, as shown in Eq. 3. The idea underlying these hybrid RANS/LES turbulence models is the use of the RANS model as a subgrid model for the LES when the flow is completely detached, while keeping the original RANS equations for the attached flows. This is achieved by modifying the wall distance of the turbulence model transport equations with a value of the order of the cell size. For the ZDES, as presented in Eq. 1, the modified wall distance $\left(\tilde{d}_{w}\right)$ equals either $d_{w}$ or $C_{D E S} \Delta$ depending on the value of $f_{D D E S}$, that is obtained through Eq. 3.

$$
\begin{aligned}
& \tilde{d}_{w}=d_{w}-f_{D D E S} \max \left(0, d_{w}-C_{D E S} \Delta\right) \\
& r_{d}=\frac{v_{t}+v}{\sqrt{U_{i j} U_{i j}} \kappa^{2} d_{w}^{2}} \\
& f_{D D E S}=1-\tanh \left[\left(8 r_{d}\right)^{3}\right]
\end{aligned}
$$

For the subgrid length scale $(\Delta), \Delta \omega$ proposed by Chauvet [14] is retained, as it prevents the delay in the formation of turbulent structures, as shown by Deck [7]. This is possible thanks to the introduction of the local vorticity unit vector components $\left(N_{i}\right)$ as weighting function of the cell size in each direction $(\Delta i)$, as presented in Eq. 6, compared to the simple $\Delta v o l$ presented in Eq. 5 that only considers the grid cell size in each direction. The use of $\Delta v o l$ or $\Delta \omega$ already suffices for avoiding the delay in the formation of the turbulent structures observed in the DDES model proposed by Spalart [6], where only $\Delta_{\max }$ (see Eq. 4) is used. Nevertheless $\Delta v o l$ or $\Delta \omega$ are not enough on their own for assuring a correct shielding of the boundary layer, on the contrary to $\Delta$ max. For this reason, Deck [7] proposed a dual behaviour of subgrid length scale, retaining the original $\Delta_{\max }$ when $f_{D D E S}<f_{d 0}$ for protecting the boundary layer while shifting into $\Delta v o l$ or $\Delta \omega$ (depending on the users choice) when $f_{D D E S}>f_{d 0}$, ensuring a rapid switch to LES, $f_{d 0}$ being a constant calibrated to 0.8 (see $7 \mathrm{~b})$.

$$
\begin{gathered}
\Delta \max =\max (\Delta x, \Delta y, \Delta z) \\
\Delta v o l=\sqrt[3]{\Delta x \Delta y \Delta z} \\
\Delta \omega=\sqrt{N_{x}^{2} \Delta y \Delta z+N_{y}^{2} \Delta z \Delta x+N_{z}^{2} \Delta x \Delta y} \\
\Delta= \begin{cases}\Delta \max & \text { if } f_{D D E S}<f_{d 0} \\
\Delta v o l \text { or } \Delta \omega & \text { if } f_{D D E S}>f_{d 0}\end{cases}
\end{gathered}
$$


In terms of RANS model, the one equation turbulence model proposed by Spalart et al. [15] is used. This model has been widely used for RANS computations and for Detached Eddy Simulations (DES) because of its accuracy, simplicity and low computational cost. Due to the triggering of the boundary layer during the experimental campaign, as shown in Figure 3 (c), the fully turbulent version of the model is retained. The transport equation used for the scalar $\tilde{v}$ is presented in Eq. 8. The reader can refer to [15] for further details.

$$
\frac{D \tilde{v}}{D t}=c_{b 1} \tilde{S} \tilde{v}+\frac{1}{\sigma}\left[\nabla \cdot((v+\tilde{v}) \nabla \tilde{v})+c_{b 2}(\nabla \tilde{v})^{2}\right]-c_{w 1} f_{w}\left[\frac{\tilde{v}}{d_{w}}\right]^{2}
$$

Concerning the numerical schemes applied, an implicit second order in time Runge-Kutta (RKI2) scheme is used with 18 inner GMRES sub-iterations, assuring a decrease of three orders of magnitude in the residuals per physical iteration. The time step $(\Delta t)$ equals $2.5 \mathrm{e}-06$ seconds $\left(T_{D} / \Delta t=1540\right)$. In space, the second order HLLC scheme proposed by Toro [16] is used.

As for the boundary conditions, the open-jet configuration proposed in the LAGOON problem statement (see [17]) is retained, matching the CEPRA19 inflow conditions, presented in Table 2. It is important to notice that these conditions slightly differ from the ones of F2, where most of the flow measurements were performed, hence minor differences are to be expected when comparing these kind of results.

\begin{tabular}{|c|c|c|c|}
\hline$\rho_{\infty}$ & $P_{\infty}$ & $T_{\infty}$ & $M_{\infty}$ \\
\hline $1.18 \mathrm{~kg} / \mathrm{m}^{3}$ & $96772.3 \mathrm{~Pa}$ & $288.39 \mathrm{~K}$ & 0.23 \\
\hline
\end{tabular}

Table 2: Boundary conditions used on the present computation extracted from [17].

are retained, as $264 \mathrm{~ms}$ of flow are computed in ZDES, representing $T / T_{D}=68.5$, but only the last $154 \mathrm{~ms}\left(T / T_{D}=40\right)$ are retained, as the first $110 \mathrm{~ms}$ are considered to be needed for assuring the convergence of the ZDES after the shift Mom URANS. The duration of this second transient phase was estimated thanks to the use of the method proposed by Mockett et al. [18], as shown in Figure 6 (b). This algorithm, was developed for detecting the transient phase duration on DES simulations through the quantification of the random error generated when estimating the different statistical
moments on a finite signal. It checks that the statistical magnitudes (mean and standard deviation) are time-invariant and also that the steady state of the signal has been achieved for a sufficiently long part of the total signal. As shown in Figure $6(\mathrm{a})$, the value of $110 \mathrm{~ms}\left(T / T_{D}=28.5\right)$ obtained when using this algorithm is very close to the value simply deduced from studying the evolution of the temporal signal.

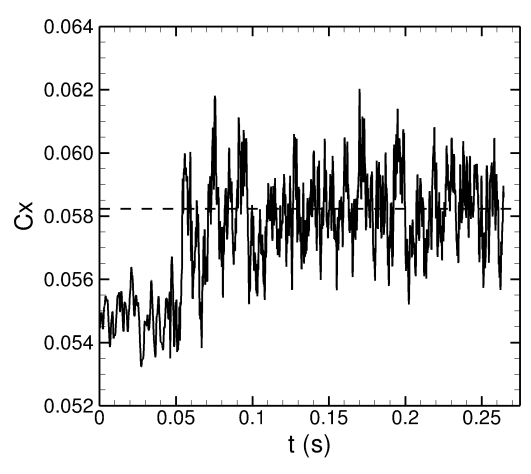

(a)

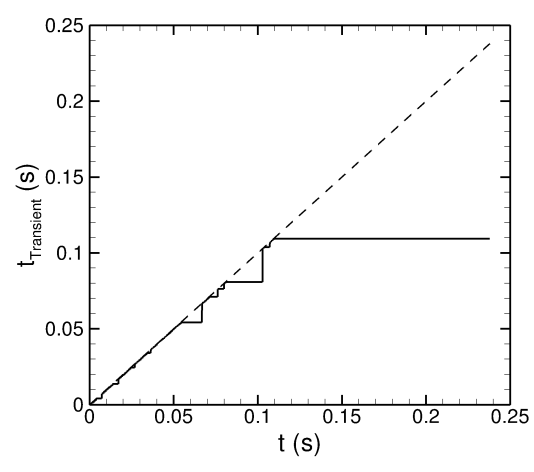

(b)

Figure 6: Drag coefficient convergence. Raw signal (a) and transient duration estimation based on Ref. [18] (b).

\subsection{Parallelism and performance}

ONERA's in-house cluster has been used for the computation. It is composed of 8000 cores with 35 TB of memory, $300 \mathrm{~TB}$ of storage and a peak performance of 115 Tflops. For the present computation, 480 Intel Xeon Ivy-Bridge 
cores were used with a clock speed of $2.5 \mathrm{GHz}$, consuming 1.5e+05 CPU hours. In terms of performance, the CEDRE code was run at $9.5 \mu \mathrm{s}$ CPU per inner sub iteration and element, or in other words, $974 \mathrm{CPU}$ hours are needed per millisecond of simulated flow. These figures are considered to be very competitive for classical CFD approaches, as can inferred from the data provided in reference [19]. Since the ultimate goal of the research in landing gear noise is to provide industry with flexible, accurate, cheap and validated solutions, in such a way that the acoustic emission can be directly addressed during the early stages of the design of a new landing gear, it is considered by the authors that these figures are of major importance.

\section{Aerodynamic results}

From the F2 wind tunnel tests briefly presented in $\S 2$, an extensive aerodynamic database has been built for the LAGOON Configuration \# 1 case, in order to assess different CFD methodologies. The most important aerodynamic comparisons are provided and commented in the present paragraph, covering time averaged and unsteady wall pressure measurements, off-body time averaged velocity fields as well as velocity spectra at different locations. Few details about the experimental campaign are also presented before comparison with the CFD results.

\subsection{Time averaged pressure measurements}

The LAGOON model was equipped with 64 type D Drück class differential pressure sensors with a working range of $\pm 6900 \mathrm{~Pa}$ ( $\pm 1 \mathrm{PSI}$ ) with respect to the wind tunnel static pressure and a data acquisition frequency of $500 \mathrm{~Hz}$. For the sake of simplicity, only the evolution of the mean pressure coefficient over the tire in the azimuth direction $\theta$ (see Figure 8), shown in Figure 7, is presented. The agreement with the experimental results obtained in F2 is very satisfying. An asymmetry between the upper part of the tire $\left(\theta<180^{\circ}\right)$ and the lower part $\left(\theta>180^{\circ}\right)$ is observed because of the presence of the leg that accelerates the flow in the upper side. The flow detachment on the middle of the tire, that corresponds to $Y / L=-0.5$, occurs at $\theta=130^{\circ}$ and $\theta=230^{\circ}$ for the upper and lower part respectively.

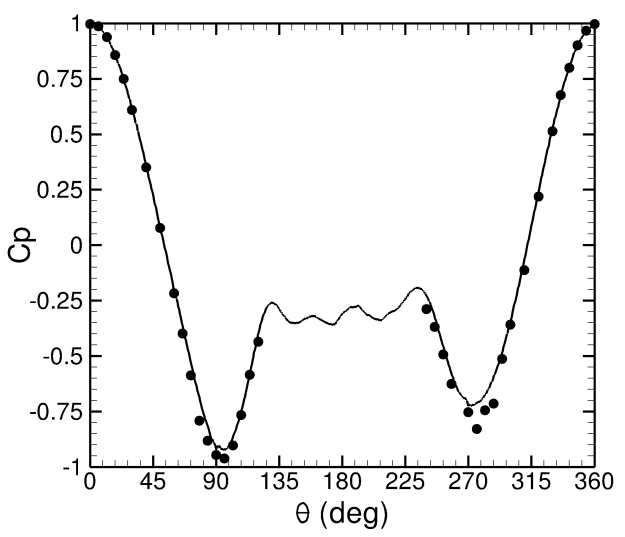

Figure 7: Evolution of the steady pressure coefficient $(\mathrm{Cp})$ over the left tire $(Y / L=-0.5)$ in the azimuth direction $\theta$. The solid line (-) represents the numerical results and the black dots $(\bullet)$ correspond to the experimental results obtained in F2

\subsection{Unsteady pressure measurements}

In terms of unsteady pressure measurement, 27 unsteady pressure transducers (Kulite ${ }^{\circledR}$ ) with a sampling frequency of $40 \mathrm{kHz}$ were installed on the LAGOON landing gear for the measurements performed in F2 and CEPRA19. The locations of some of those Kulites are presented in Figures 8 and 9. 


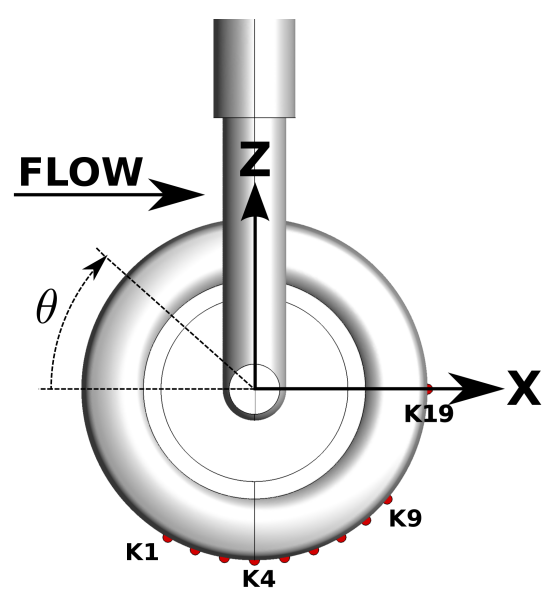

Figure 8: Experimental unsteady pressure transducers (Kulites) over the right tire for measurements in the azimuth direction. The left wheel has been removed for visualization purposes
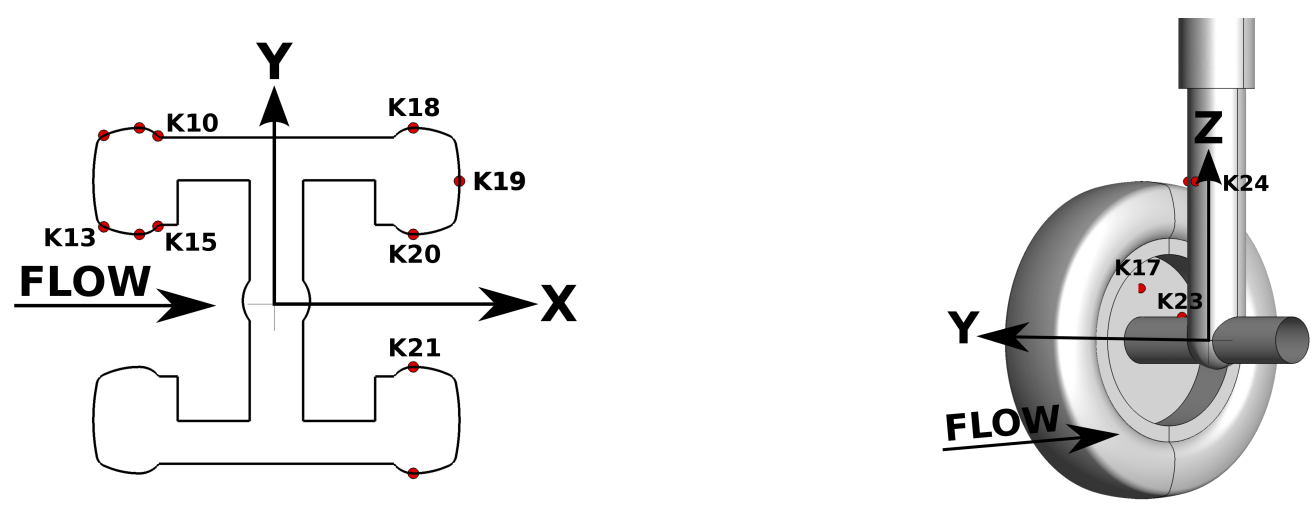

Figure 9: Experimental unsteady pressure transducers (Kulites) locations at $Z / D=0$ (left). Kulites location inside the cavity, wheel axle and leg (right). The left wheel has been removed for visualization purposes

All the numerical power spectral densities (PSDs) shown in the following paragraphs are calculated using 17 overlapping blocks (with a $67 \%$ overlapping) coupled with a Hann windowing and using the $154 \mathrm{~ms}\left(T / T_{D}=40\right)$ time signal available. This post-processing leads to a frequency resolution of $\Delta f=40.8 \mathrm{~Hz}$, compared to the $10 \mathrm{~Hz}$ resolution of the experimental results. Available duration of experimental time signals is $20 \mathrm{~s}\left(T / T_{D}=5195\right)$ and PSDs are computed from 192 non-overlapping blocks leading to a finer frequency resolution and better statistically converged results.

Figure 10 presents the PSDs of selected wall pressure transducers along the left wheel mid-plan at $Y / L=-0.5$, for different azimuthal positions $\theta$. Overall good agreement between the computed and measured PSDs is observed. For K1 and K4 transducers (Figure 10 top) the computed PSD agree well with the measurements up to $2 \mathrm{kHz}$. Above this frequency, the experimental PSDs exhibit a plateau from 2 to $10 \mathrm{kHz}$ instead of progressive decay of the levels, which is probably due to the boundary layer tripping devices (see Figure 3 (right)), that were located close to the K1 position, and not reproduced in the computation. The influence of this tripping is still perceived at $\mathrm{K} 4,30^{\circ}$ later, and completely disappears afterwards, as for example, in K9, where the flow is detached, (Figure 10 bottom left). At this position, the agreement with the experimental results is good up to $4 \mathrm{kHz}$. From K1 to K9 a gradual increase of the fluctuating levels is observed, while the K19 transducer exhibits lower values. This decrease at the $\theta=180^{\circ}$ position is quite marked on the experimental results and is not fully reproduced by the computation. 


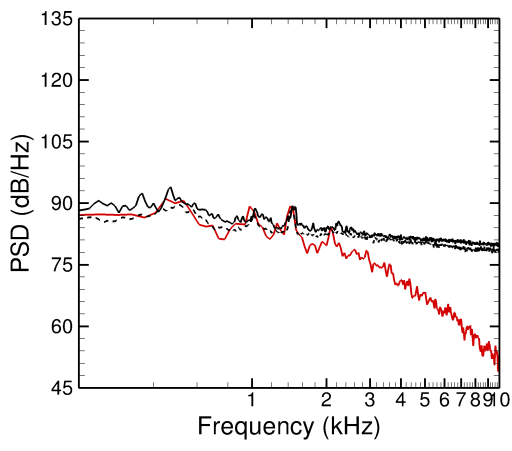

(a) $\mathrm{K} 1$

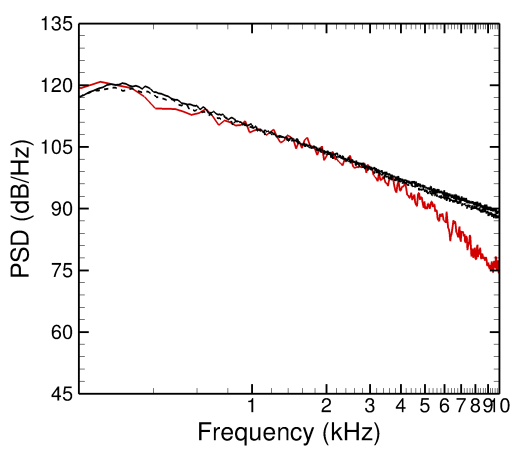

(c) $\mathrm{K} 9$

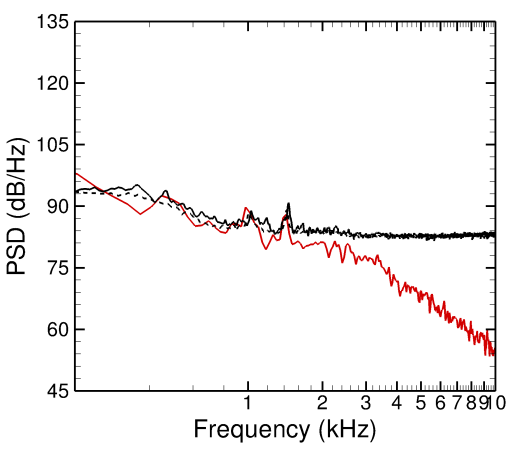

(b) $\mathrm{K} 4$

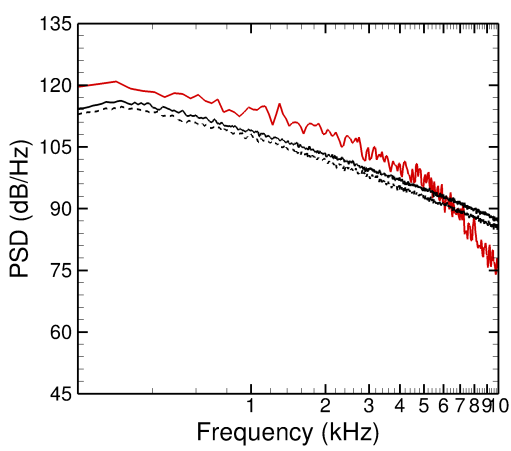

(d) K19

Figure 10: Power spectral density (PSD) of the fluctuating pressure measured at transducer K1 (a), K4 (b), K9 (c) and K19 (d). The solid red line $(-)$ represents the numerical results, the solid black line (-) corresponds to the experimental results obtained in F2 and the dashed line (--) to CEPRA19

To further analyse the pressure fluctuating levels along the wheel, Figure 11 presents the distribution of the root mean square (RMS) of $\mathrm{Cp}$ values, $C p_{R M S}$. A local minimum occurs in the $180^{\circ}$ region, whereas two maxima appears ar $170^{\circ}$ and $210^{\circ}$. In order to shed light on these variations, PSDs of the transducers along the wheel mid-plane were integrated in the $[200 \mathrm{~Hz}-20 \mathrm{kHz}]$ range, corresponding to the range of the band pass filter used during the experimental campaings. Integration from numerical and experimental transducers show very similar levels except for K19, where experimental results do present some scatter between F2 (•) and CEPRA19 (O) tests, as already shown in Figure 10. These results seem to point out that this location is very sensitive to small changes in the boundary conditions. One can also assume that the whole region between the two maxima of $C p_{R M S}$ is sensitive to the boundary conditions and makes the prediction of the flow in terms of spectral content tricky. 


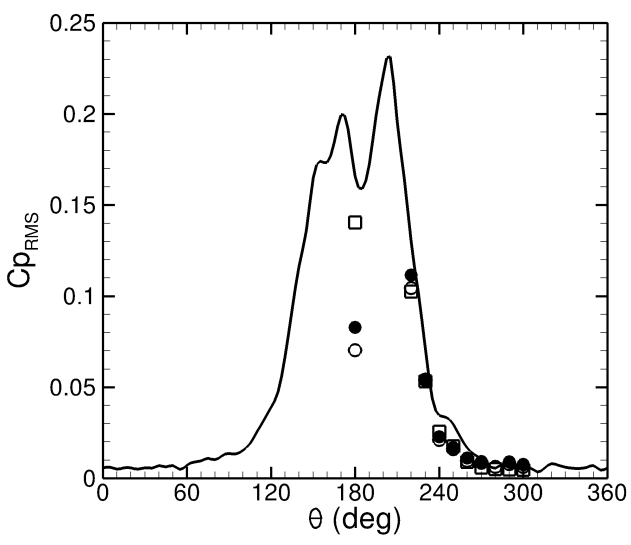

Figure 11: Evolution of the RMS pressure coefficient $\left(C p_{R M S}\right)$ over the left tire in the azimuth direction $\theta$. The solid line $(-)$ represents the numerical results obtained through statistical averaging, the black dots $(\bullet)$ correspond to the experimental results obtained in F2 for the different unsteady pressure transducers integrated from $200 \mathrm{~Hz}$ to $20 \mathrm{kHz}$, empty circles (O) correspond to CEPRA19 ones and the empty squares, ( $\square$ ) represent the numerical results obtained at the same location of the experimental sensors integrated in the same frequency band.

Considering the flow between the wheels, several sensors (K15, K17, K20 and K23) are of great interest (see Figure 9) and their PSDs are presented on Figure 12. The first one, K15 (Figure 12 top left) corresponds to a location where the boundary layer of the tire has already detached and a shear layer has been formed grazing the wheel cavities. Two tones emerge from the cavity at frequencies $1020 \mathrm{~Hz}$ and $1500 \mathrm{~Hz}$ (from the analysis of the experimental results, there are also smaller tones at $470 \mathrm{~Hz}$ and $590 \mathrm{~Hz}$ ). The amplitude of these tones is well reproduced by the numerical simulation, while a slight frequency shift of about $30 \mathrm{~Hz}$ is observed that is within the frequency resolution of the computed PSD $(\Delta f=40.8 \mathrm{~Hz})$. The nature of these tones is still an open question. Casalino et al. [20] explain the first tone by the existence of a planar mode between the two wheel cavity floors, while the second tone could be the results of an azimuthal mode related to the cavity edge to edge distance. On this figure, the computation seems to overestimate the levels in the low frequency range, below $1 \mathrm{kHz}$, which could be associated with a larger recirculating bubble between the upstream detachment point on the tire and the cavity upstream edge.

Sensors K17 and K23 (Figure 12 bottom) measure the unsteadiness of the flow inside the cavity and over the wheel axle respectively. For these two locations the prediction of the spectrum is very accurate up to about $7 \mathrm{kHz}$.

Finally, K20 (Figure 12 top right) is placed next to the shear layer reattachment at the downstream part of the right tire. Once again, the numerical solution is in very good agreement with the experimental results obtained in the two wind tunnels up to $\approx 6 \mathrm{kHz}$. 


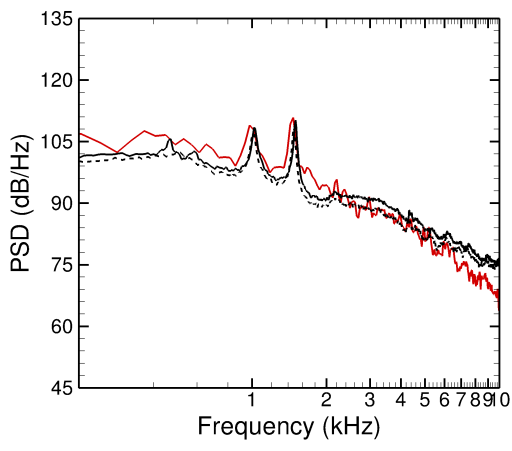

(a) $\mathrm{K} 15$

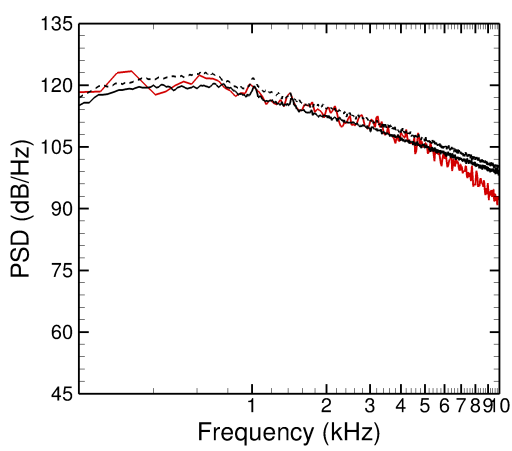

(c) K17

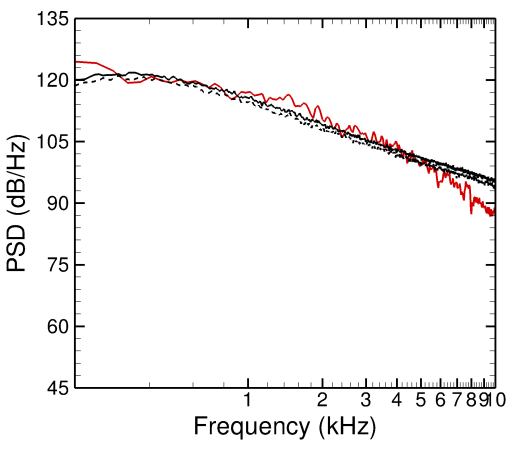

(b) K20

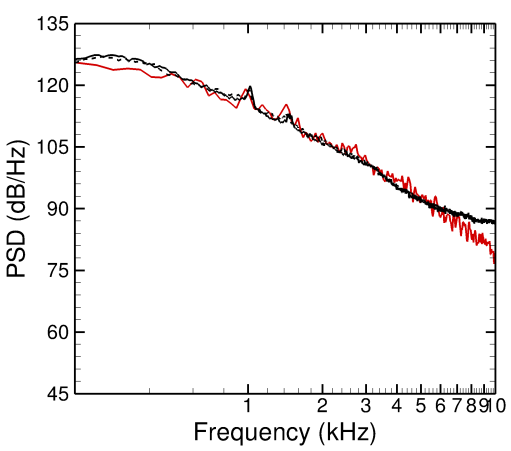

(d) K23

Figure 12: Power spectral density (PSD) of the fluctuating pressure measured at transducers K15 (a), K17 (c), K20 (b) and K23 (d). The solid red line (-) represents the numerical results, the solid black line (-) corresponds to the experimental results obtained in F2 and the dashed line (- $)$ to CEPRA19

\subsection{Time averaged flow}

After the analysis of the steady and unsteady wall pressures, the present section is focused on the time averaged, sured the streamwise velocity $U$, aligned with the $X$ axis (see Figure 3 (a)), and the crosswise velocity component $\mathrm{V}$ (aligned with Y) in different planes, Laser Doppler Velocimetry (LDV) measured U and the vertical velocity W (oriented towards $\mathrm{Z}$ ) along different lines, and in limited planes, were used. The numerical results obtained will then be compared to these experimental ones.

Firstly, the flow behind the landing gear wheels at $Z / D=0$, is plotted in Figures 13 and 14. From the analysis of these figures, it appears that the flow at this location is well reproduced, both in terms of time-averaged and RMS velocity components. It is important to notice that the streamwise and crosswise velocity components were obtained through PIV measurements, while the vertical velocity was measured with LDV on a reduced window (represented by a black square on the computational results side).

A detailed analysis of Figure 13 allows to distinguish a three peak "crown" shaped wake, that develops up to $X / D=1.25$. These three peaks come from the wake of the two wheels that merge between them while, at the same time, a faster wake coming from the leg and axle of the landing gear (a trace of this wake can be seen at $[X / D=0.5, Y / L=0]$ ) pushes the wake resulting from the merge of those of the wheels downstream. In terms of crosswise velocity $\mathrm{V}$, the flow tends to push the wake inwards. It is interesting to notice that, in the vicinity of the vertical component presents a very steep gradient, with a sudden inversion of the sign of W. In terms of RMS, see 
Figure 14, two aspects must be underlined. The first one concerns the $U_{R M S}$ values, that present an increase of the levels at $Y / L \approx \pm 0.75$. It corresponds to the wake coming from the external part of the tires, that rapidly merges with the rest of the flow and vanishes after $X / D=1$. Secondly, $W_{R M S}$ levels are dominating when compared to the other components, not only in terms of levels but also in extension. This intense $W_{R M S}$ seems not to correspond to a flapping of the wake, as will be seen in $\$ 4.4$, as the velocity spectra at those locations only presents the classical exponential decrease without the existence of any tone.

In order to better compare the results with the experiments and highlight the differences, several lines at different locations are extracted. In Figure 15, the different velocity magnitudes are compared against the ones measured at F2 through LDV and against the PIV whenever possible. The first thing to be observed is the mismatch on the infinite streamwise velocities between the measurements and the computation. This mismatch is associated with the boundary conditions used for the computation, that are closer to CEPRA19 ones. This increase of the streamwise velocity is not reproduced in the same way by LDV and PIV measurements, giving a possible estimate of the uncertainty in the velocity measurements. In terms of vertical velocity $(\mathrm{W})$, there is a small discrepancy with respect to the experimental results at $Y / L=-0.6$, nevertheless, given the apparent symmetry of the figure it seems logical to think that this disagreement corresponds to a default on the measurements. Finally, as regards the RMS values, there is a clear underestimation of the computed streamwise velocity component except for the lateral peaks, probably corresponding to the flow detachment on the external side of the tires. For the RMS vertical velocity, the levels are well reproduced behind the wheels but underestimated in the inter-wheel region. 

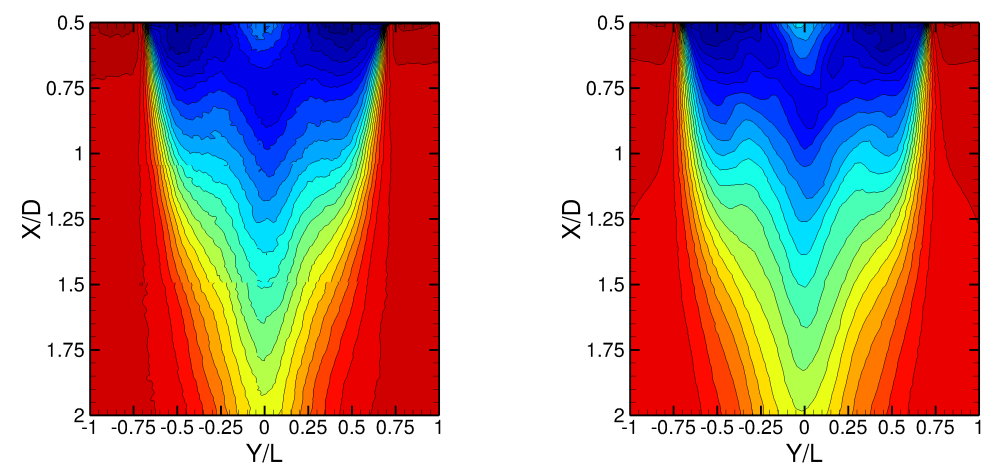

$\mathrm{U} / \mathrm{U}_{\infty}$
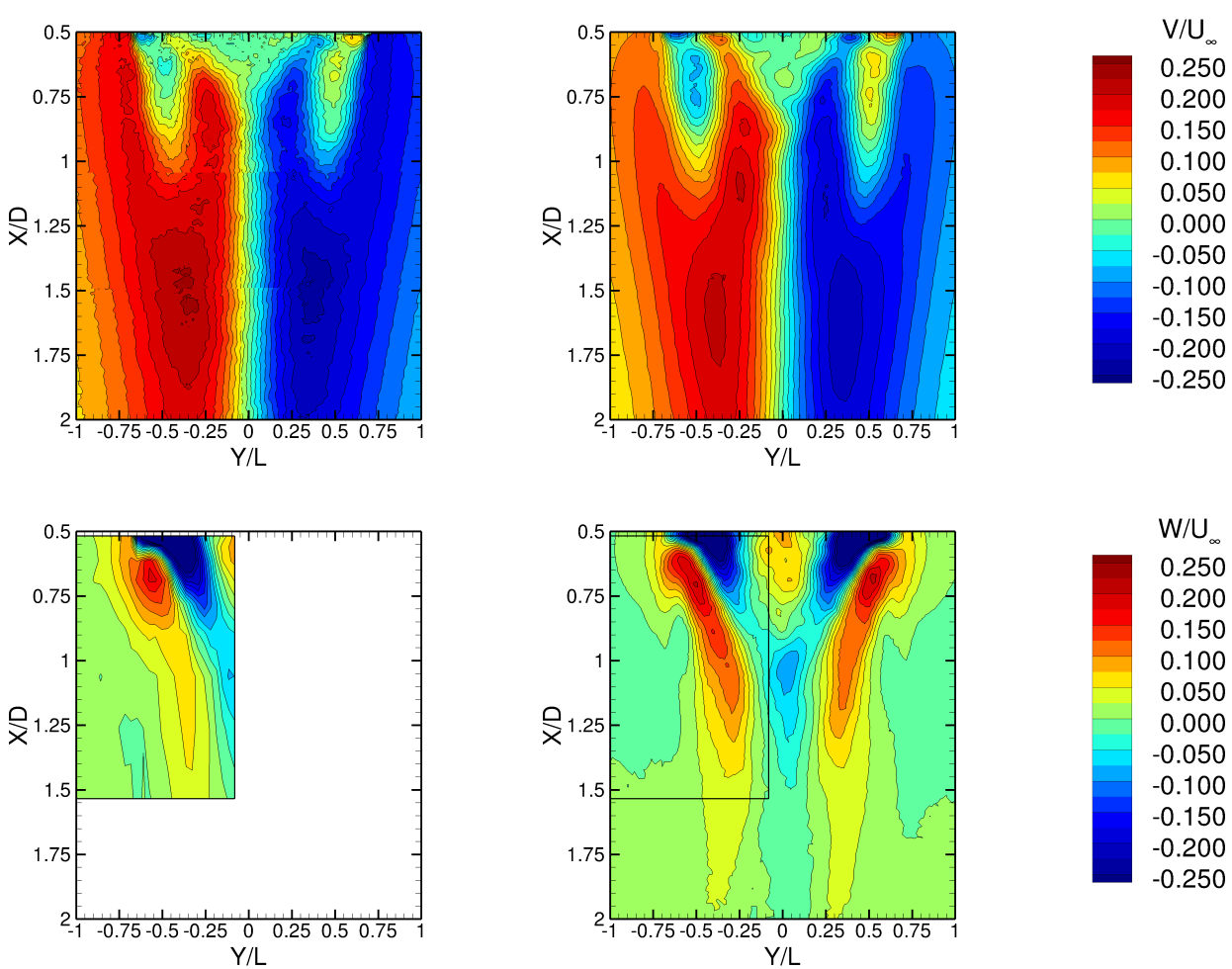

W/U

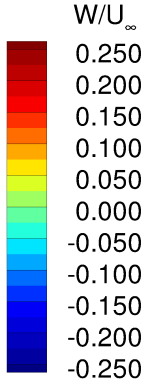

Figure 13: Off-body time averaged flow measurements at $Z / D=0$. From top to bottom: streamwise velocity (U), crosswise velocity (V) and vertical velocity (W). Experimental results obtained in F2 (left) and computation results (right) 

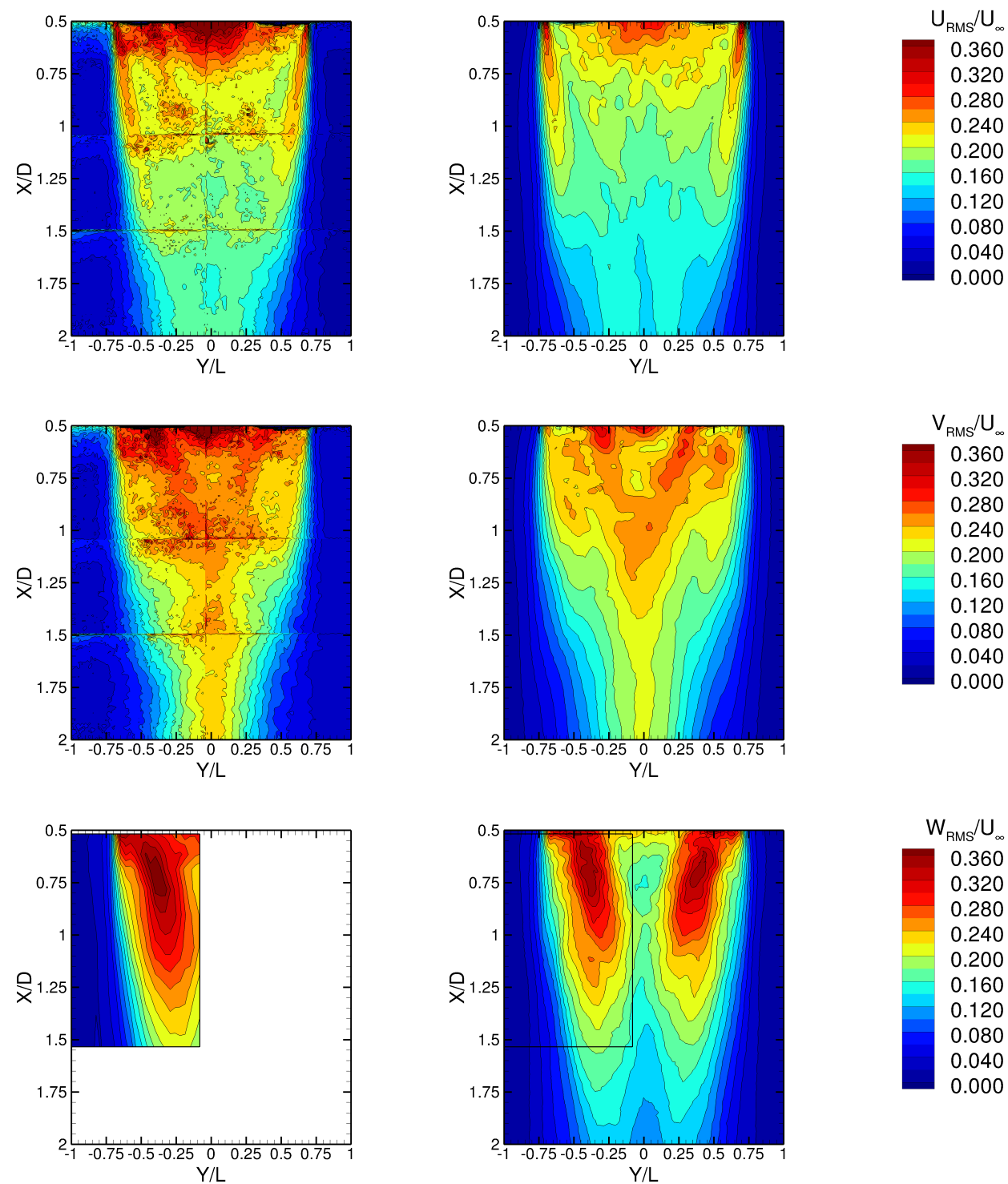

Figure 14: Off-body RMS flow measurements at $Z / D=0$. From top to bottom: streamwise velocity (U), crosswise velocity (V) and vertical velocity (W). Experimental results obtained in F2 (left) and computational results (right)

In Figure 16, the streamwise velocity (U) is extracted from the PIV and numerical plane $Z / D=0$ along two crosswise lines ( $\mathrm{a}$ and $\mathrm{b}$ ) located behind the wheels at $X / D=1$ and $X / D=1.5$ respectively, as well as two streamwise lines $(\mathrm{c}$ and $\mathrm{d})$ found in the landing gear symmetry plane $(Y / D=0)$ and at the middle of the right wheel $(Y / L=0.5)$. These plots show that the wake of the wheels is accurately reproduced, with a small underestimation of the velocity behind the right wheel downstream of the landing gear. A closer analysis of these figures show an slightly wider wake at $X / D=1$ that remains at least up to $X / D=1.5$ (see Figure $16(\mathrm{a}-\mathrm{b})$ ), but the velocity deficit and shape of the profile are well reproduced. Concerning the streamwise development of the wake, there seems to be an overestimation of the velocity between the wheels, at $Y / L=0$ for stations below $X / D=0.8$ (Figure $16 \mathrm{c}$ ), nevertheless, once this point is exceeded the good tendency and levels are recovered. With respect to the wake developing behind the right tire at $Y / L=0.5$, there is a good agreement with the experiments up to $X / D=0.8$, but after this point, the numerical solution slightly diverges with respect to the experiments in terms of levels, while keeping the good tendency (see Figure 16 
d). The faster recovery of the infinite velocity in measurements can be attributed to the closed section of the F2 wind tunnel as previously mentioned.

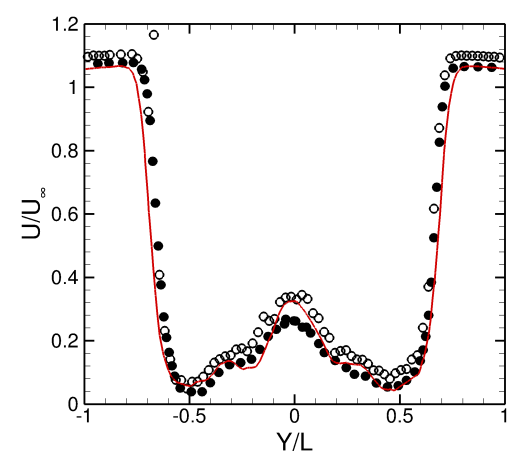

(a)

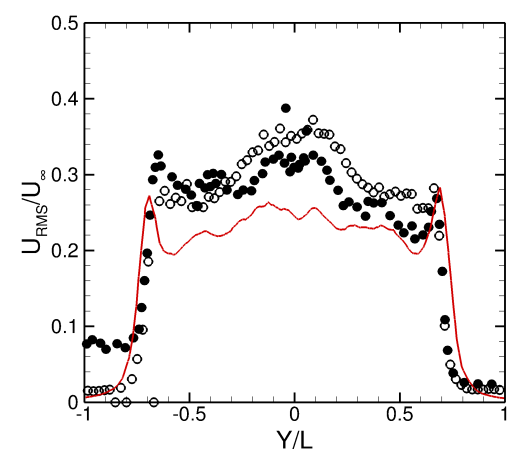

(c)

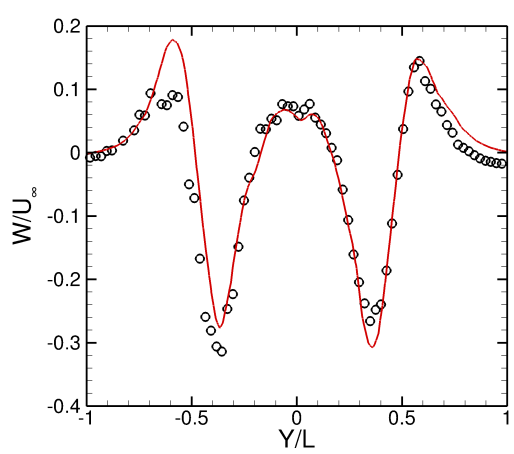

(b)

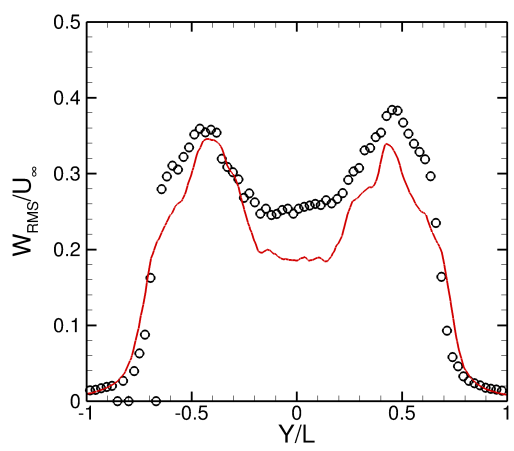

(d)

Figure 15: Steady velocity in the wake of the landing gear in the crosswise direction (Y) at $Z / D=0$ and $X / D=0.6$. Stream-wise velocity (a), vertical velocity (b), RMS streamwise velocity (c) and RMS vertical velocity (d). The solid line (-) represents the numerical results, circles (O) correspond to the LDV measurements, and dots $(\bullet)$ are extracted from the PIV planes obtained in F2 


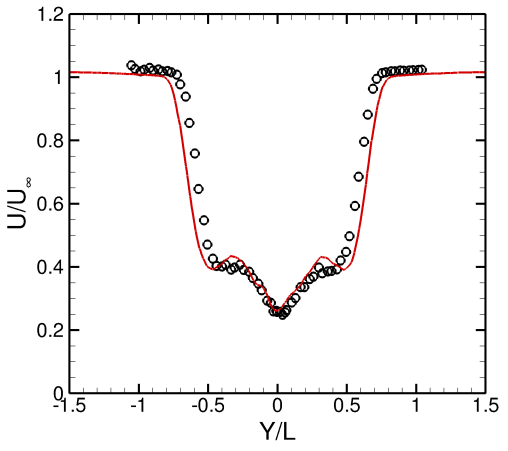

(a)

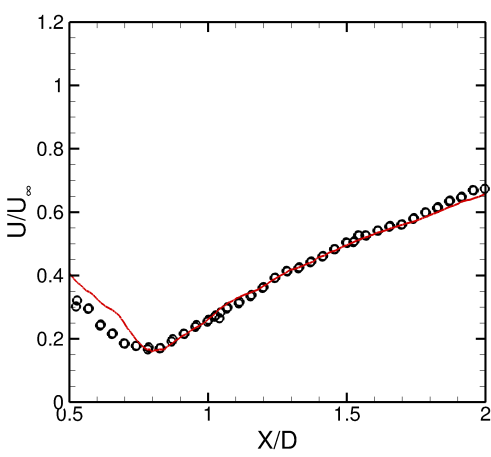

(c)

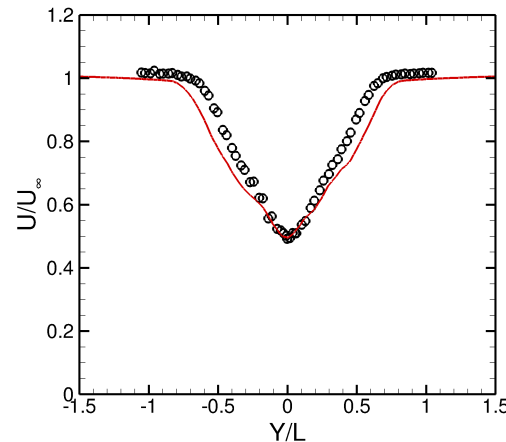

(b)

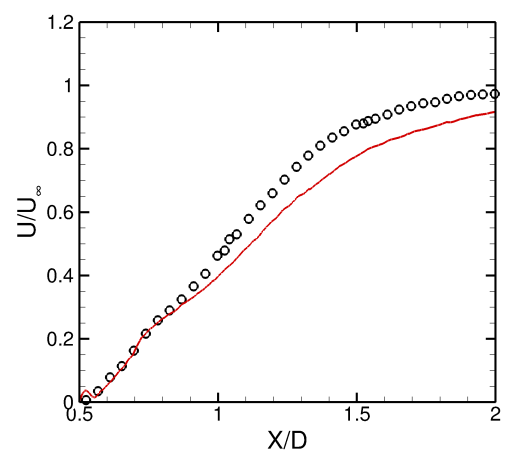

(d)

Figure 16: Stream-wise velocity component (U) extracted from plane $Z / D=0$. Lines at $X / D=1(\mathrm{a}), X / D=1.5(\mathrm{~b}), Y / L=0(\mathrm{c})$ and $Y / L=0.5$ $(\mathrm{d})$. The solid line $(-)$ represents the numerical results and circles $(O)$ correspond to the experimental results obtained in F2

Moving upwards in the landing gear wake, the PIV plane $Z / D=0.347$ (see Figure 17) focuses in the area of interaction of the wheels-leg wake. The flow topology in this plane appears to differ from that observed at $Z / D=0$

(see Figure 13). In first place the three peak "crown" shaped wake has disappeared, instead a more homogeneous wake appears downstream of the tires, from $X / D=0.6$ to $X / D=1.5$. This streamwise displacement of the wake with respect to $Z / D=0$ is associated with the deviation of the wake towards the leg and related to the strong positive $\mathrm{W}$ velocity component in the inter-wheel region. A small flow detachment over the interior part of the tires exists around $Y / L \approx \pm 0.375$ and the low streamwise velocity zone associated extends up to $X / D=0.65$. At the same time, a strong increase in the streamwise velocity of the flow is located at $Y / L \approx \pm 0.15$, that is due to the acceleration generated when the flow goes in between the upper part of the tire and the leg. In terms of crosswise velocity, the velocity is now reversed, when compared to $Z / D=0$, and now the flow evades from $Y / D=0$ due to the effect of the curvature of the tires. At the same time, the levels have been globally greatly reduced and the maxima are now localized only behind the wheels. On the other hand, the vertical velocity component $(\mathrm{W})$ presents a much more homogeneous pattern, with the flow following the curvature of the tires $(W<0)$ and moving towards the leg in between the wheels $(W>0)$. Several lines extracted from this plane and shown in Figure 18 present a very close agreement with the experimental results. Minor discrepancies are observed for the value of the minima of streamwise velocity component (U) at the lines $X / D=1$ and $Y / L=0$, but it remains that the prediction of the width and development of the wake is very accurate.

For the plane $Z / D=0.793$ presented in Figure 19, a good agreement with the measurements for the different magnitudes considered is found. The flow topology is very similar to the flow observed for around a cylinder. 

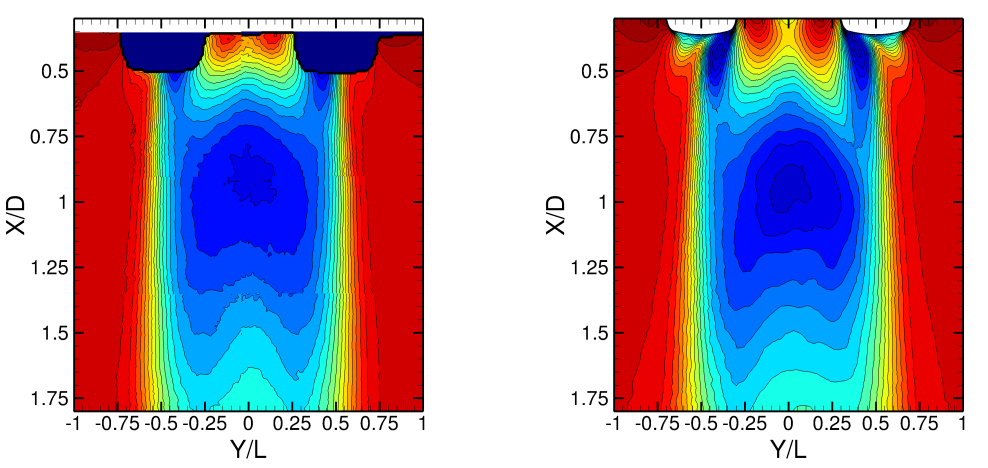

$\mathrm{U} / \mathrm{U}_{\infty}$
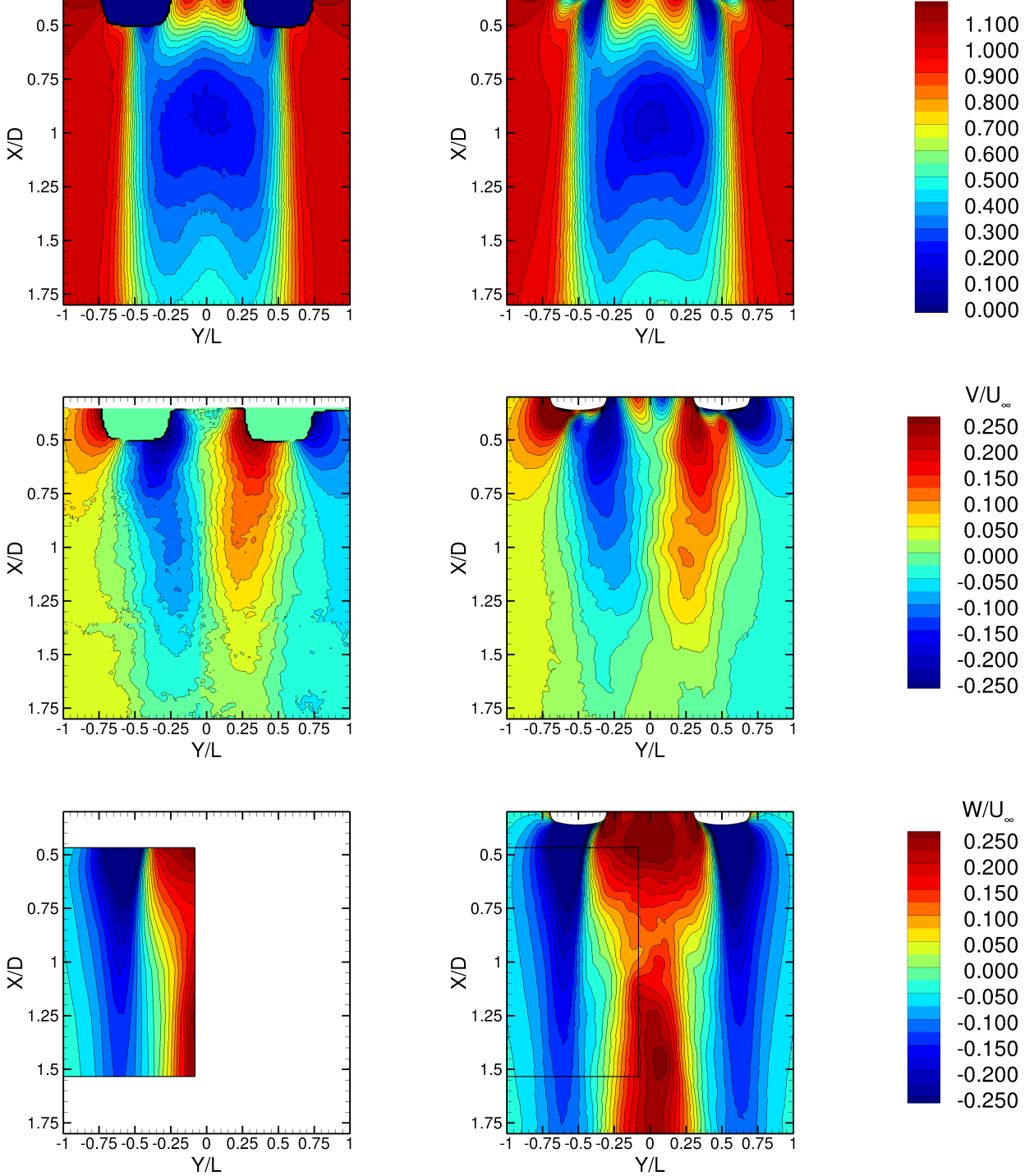

W/U

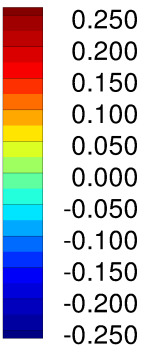

Figure 17: Off-body time averaged flow measurements at $Z / D=0.347$. From top to bottom: streamwise velocity (U), crosswise velocity (V) and vertical velocity (W). Experimental results obtained in F2 (left) and computational results (right) 


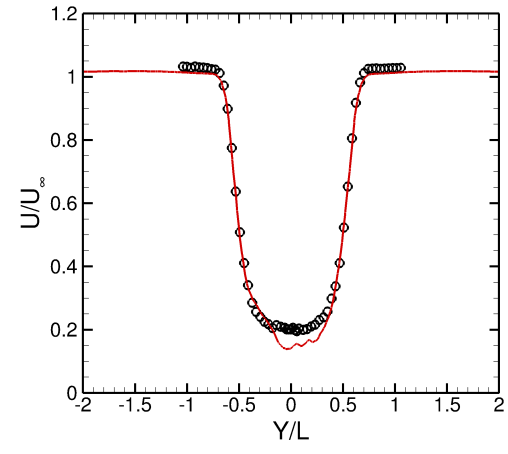

(a)

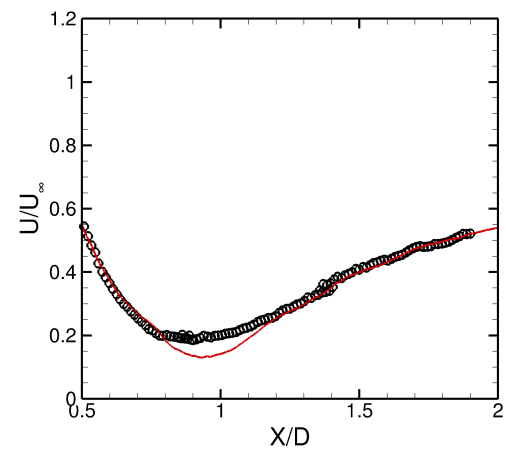

(c)

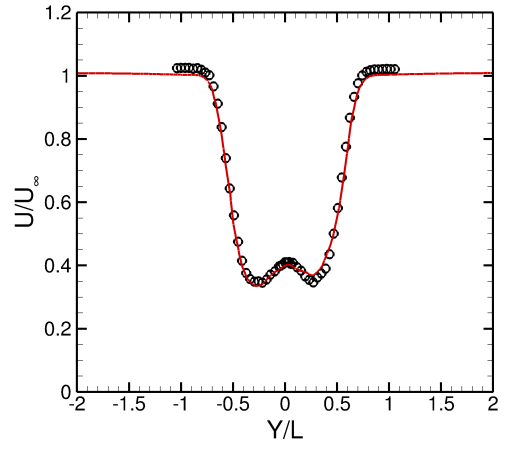

(b)

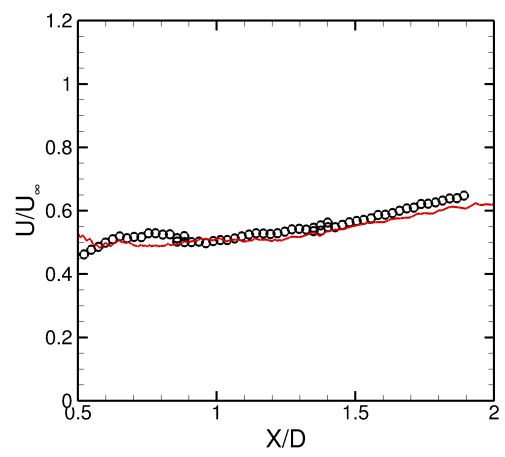

(d)

Figure 18: Stream-wise velocity component (U) extracted from PIV plane $Z / D=0.347$. Lines $X / D=1$ (a), $X / D=1.5$ (b), $Y / L=0$ (c) and $Y / L=0.5$ (d). The solid line (-) represents the numerical results while the circles (O) correspond to the experimental results obtained in F2 

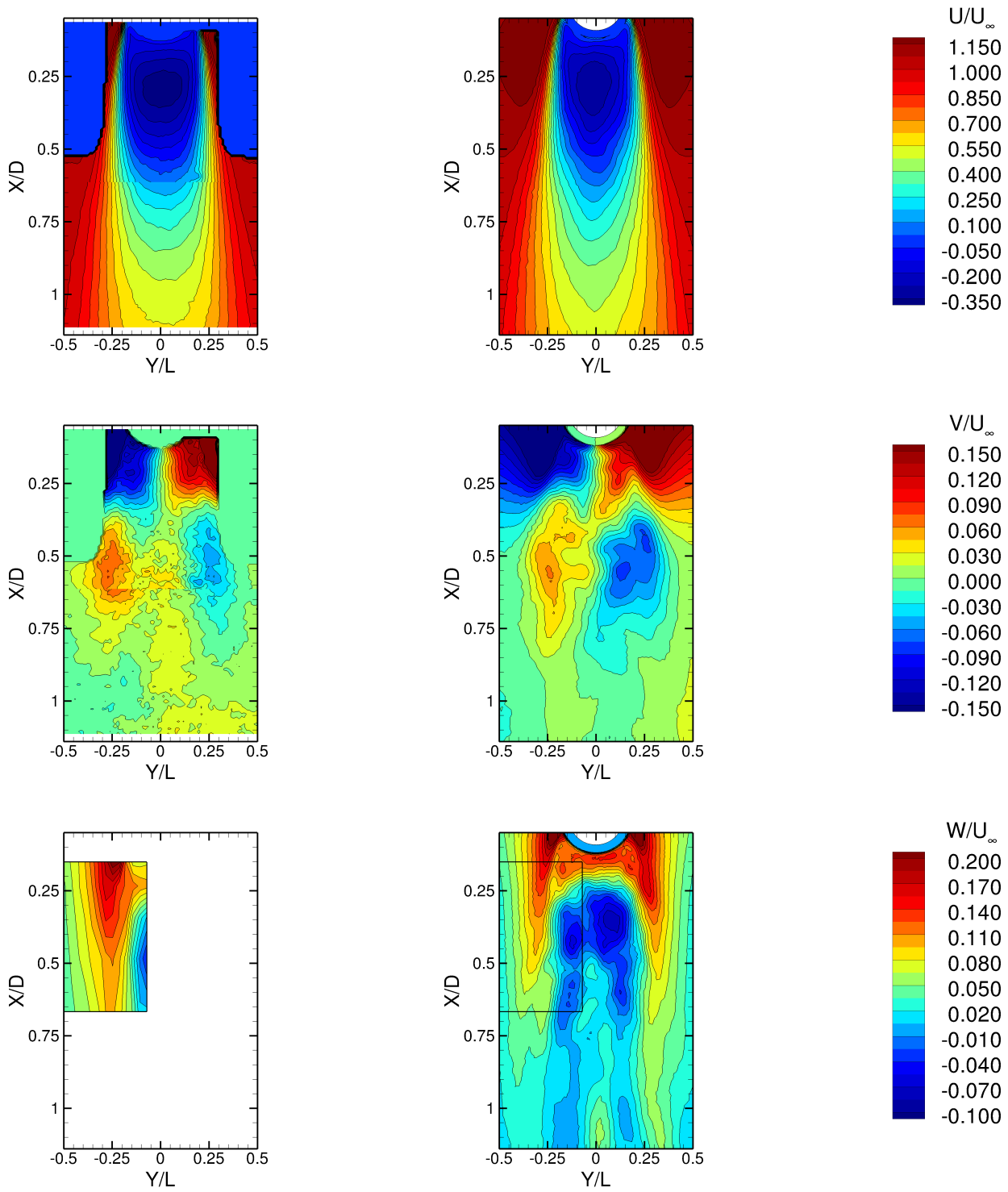

W/U

0.200

0.170

0.140

0.110

0.080

0.050

0.020

$-0.010$

$-0.040$

$-0.070$

$-0.100$

Figure 19: Off-body time averaged flow measurements at $Z / D=0.793$. From top to bottom: streamwise velocity (U), crosswise velocity (V) and vertical velocity (W). Experimental results obtained in F2 (left) and computational results (right)

Finally, the LDV measurements also allowed to access the boundary layer velocity profiles at different locations of the wheel. In Figure 20, the velocity profile at $\theta=270^{\circ}$ is compared with the computational results. The good agreement with experiments seems to prove that, despite the boundary layer triggering used in the experiments, the one-equation Spalart-Allmaras fully turbulent turbulence model is very well adapted for modelling turbulent attached boundary layers over the landing gears, without the need of modelling the transition stripes. 


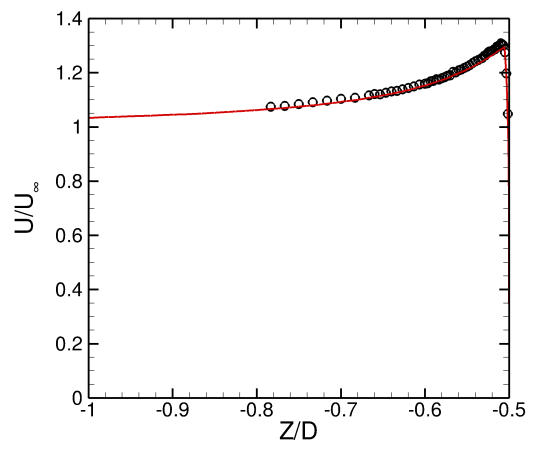

(a)

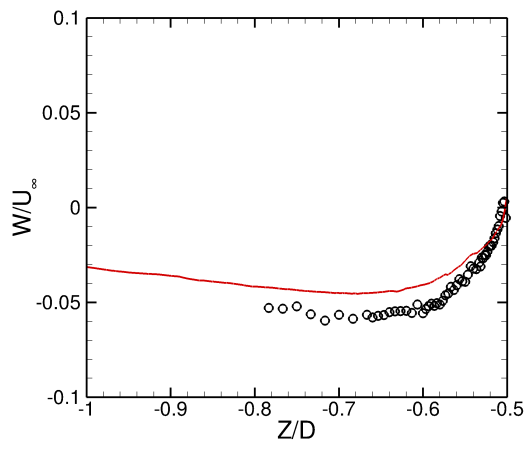

(b)

Figure 20: Steady LDV2D measurements of the boundary layer of the landing gear at $\theta=270^{\circ}$. Stream-wise velocity (a) and vertical velocity (b). The solid red line (-) represents the numerical results while the black circles $(\mathrm{O})$ correspond to the experimental results obtained in F2

\subsection{Unsteady flow}

During the experimental campaign at F2, an extensive use of the unsteady LDV was made with as much as 50 locations considered. Few locations (showed in Figure 21) have been selected for comparison in Figure 22, all of them located in the plane $Z / D=0$. For the sake of simplicity only for the streamwise velocity component (U) PSD is plotted.

The streamwise velocity spectra obtained from simulation are in quite good agreement with the measurements up to frequencies around $2 \mathrm{kHz}$. Up to this frequency, the decay of the spectra are quite similar. It is noticeable that the computation overestimates the PSD levels for P1 and P4, i.e. in the right wheel wake whereas the points P2 and P3 present a better agreement with the unsteady measurements than what could be expected from the RMS values at the same locations (see Figure 14 top), where an underestimation of the streamwise RMS values appeared in between the wheels at $X / D=0.5$.

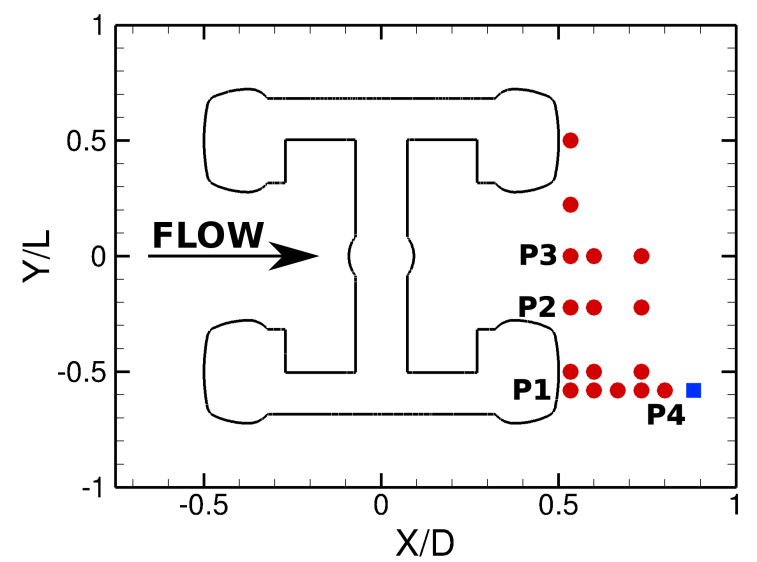

Figure 21: Position of the experimental unsteady 2D-LDV measurement points in the plane $Z / D=0$. 


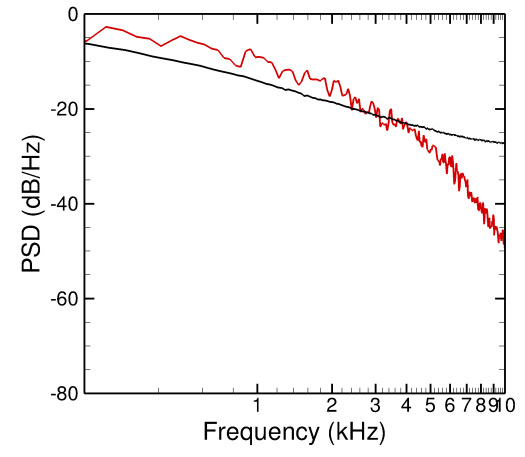

(a) P1

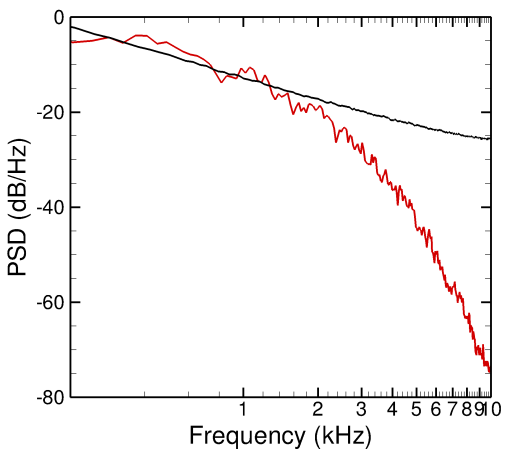

(c) P3

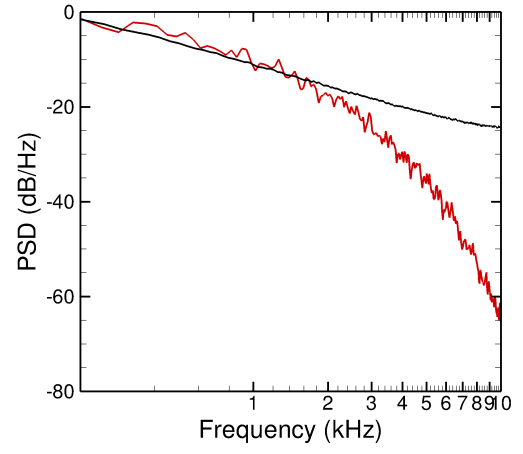

(b) P2

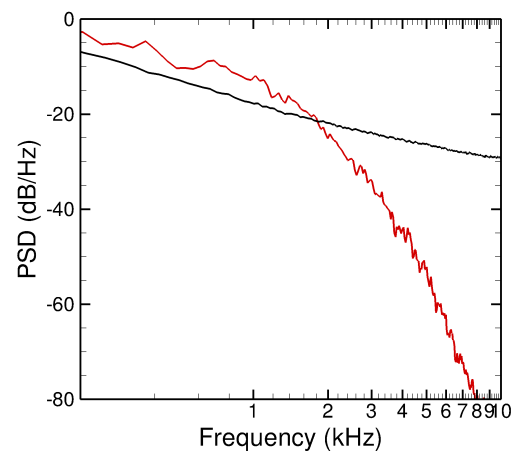

(d) P4

Figure 22: Stream-wise velocity component (U) power spectral density measured at points P1 (a), P2 (b), P3 (c) and P4 (d) (see Figure 21 ). The red line (-) represents the numerical results while the black line (-) corresponds to the experimental results obtained in F2

The correlation of the different velocity components in the wake of the landing gear has also been addressed. For this purpose, the time signal of several points distributed along the $Y / D=-0.383$ line at the plane $Z / D=0$ have been used. The evolution of the correlation function $R_{i i}$ in presented in Figure 23 (a) only for the streamwise velocity component, and is compared against the experimental results obtained at F2. The reference signal used was located at $[X / D=0.87 Y / D=-0.383 Z / D=0]$, and is represented in Figure 21 by $\boldsymbol{~}$. Secondly, analysing the decorrelation of the signals at $\tau=0$, presented in Figure 23 (b) for the different velocity components, the integral length scale of the turbulence at this location can be extracted, obtaining $L_{U U}=38 \mathrm{~mm}$ for the numerical simulation, compared to the $L_{U U}=44 \mathrm{~mm}$ obtained from F2 measurements. The integral length scale associated to the other two velocity components, $L_{V V}$ and $L_{W W}$, are very similar with a value of about $29 \mathrm{~mm}$. These values have been obtained by intersecting the tangent line to each curve at $\Delta x=0$ with the abscissae axis. 


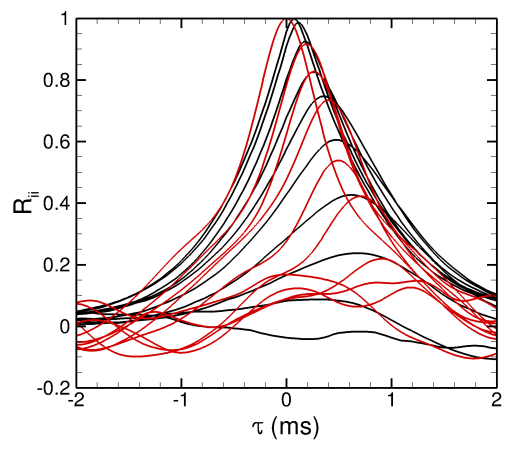

(a)

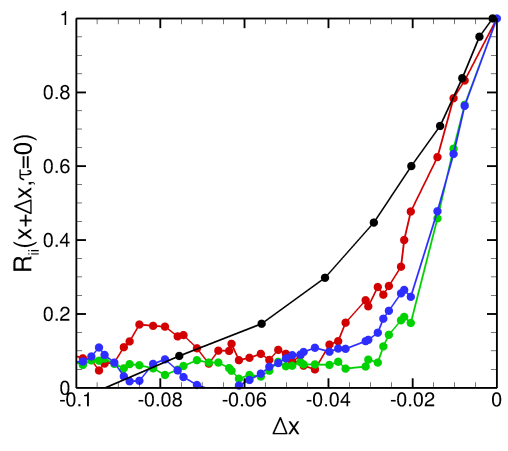

(b)

Figure 23: Evolution of the streamwise velocity correlation $R_{U^{\prime} U^{\prime}}$ in the streamwise direction at $[Y / D=-0.383 Z / D=0]$ using as reference the signal obtained at $[X / D=0.87 Y / D=-0.383 Z / D=0]$, represented in Figure 21 by (a). Numerical results $(-)$ vs $\mathrm{F} 2$ results $(-)$. Attenuation of the correlation $R_{i i}$ in the wake of the landing gear at $\tau=0(\mathrm{~b}) . R_{U^{\prime} U^{\prime}}(\bullet), R_{V^{\prime} V^{\prime}}(\bullet), R_{W^{\prime} W^{\prime}}(\bullet)$ and $R_{U^{\prime} U^{\prime}}(\bullet)$ for F2 measurements

\subsection{Topology of the flow}

In the previous sections several aerodynamic results have been compared against the experimental ones, allowing to prove the accuracy of the numerical solution performed. In the present section, those results are going to be used in order to better understand the topology of the flow around the LAGOON landing gear.

To begin with, the time averaged skin friction coefficient and friction lines associated are presented in Figure 24. In parallel, a comparison of the topology of the shear lines with the iso-surface of total pressure presented in Figure 25 is performed.

The flow detaches at the internal side of the tires due to the curvature, as shown in Figure 25 (right), the shear layer generated because of this detachment is highly deviated due to the presence of the wheel axle, merging downstream with the detached flow coming from the upper and lower part of the tire.

As regards the external rim of the wheel (Figure 24 left), a vertical line on the flat part of the tire represents the reattachment of flow. Upstream, a quasi two-dimensional re-circulation bubble is found. A closer study of the figure shows the presence of a smaller secondary bubble along the curvature of the tire. The presence of the main recirculation bubble is also visible in the iso-surface of total pressure (see Figure 25 (left)). After the reattachment of the flow, the flow remains aligned with the $\mathrm{X}$ direction until it detaches at the downstream part of the tire, merging with the flow that develops around the tire.

Considering the downstream part of the geometry, presented in Figure 24 (right), the flow detachment over the tire itself presents a triangular shape. The flow at the center of the tires $(Y / L \approx=0.5)$ remains longer attached, especially in the internal side of the tire, where, due to the presence of the leg, the flow accelerates preventing an earlier detachment. Finally the wake of the external and internal part of the tires, merges with the one coming from the leg and the wheel axle, as shown in Figure 25 (left). 

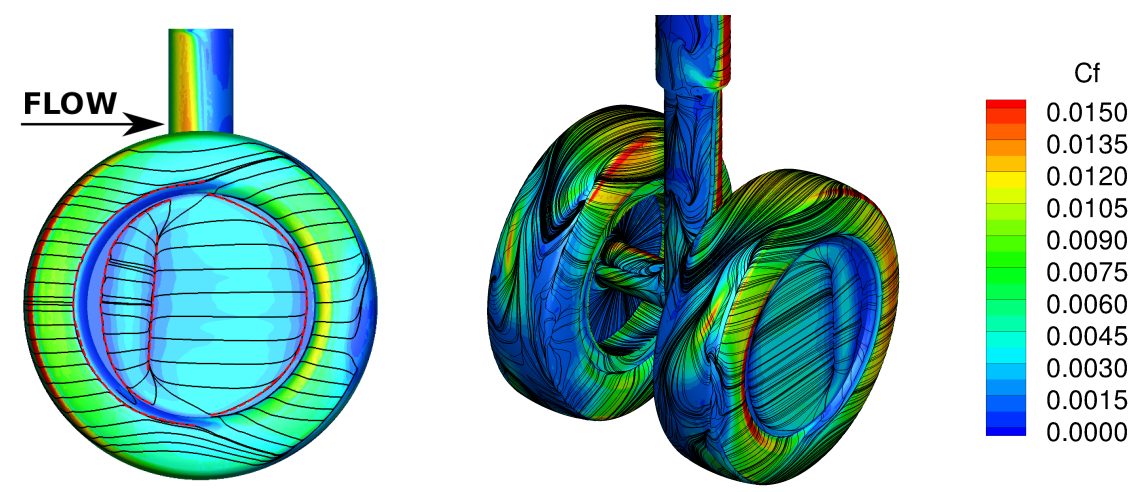

Figure 24: Skin friction coefficient and shear lines seen from the side (left) and downstream (right) part of the landing gear.
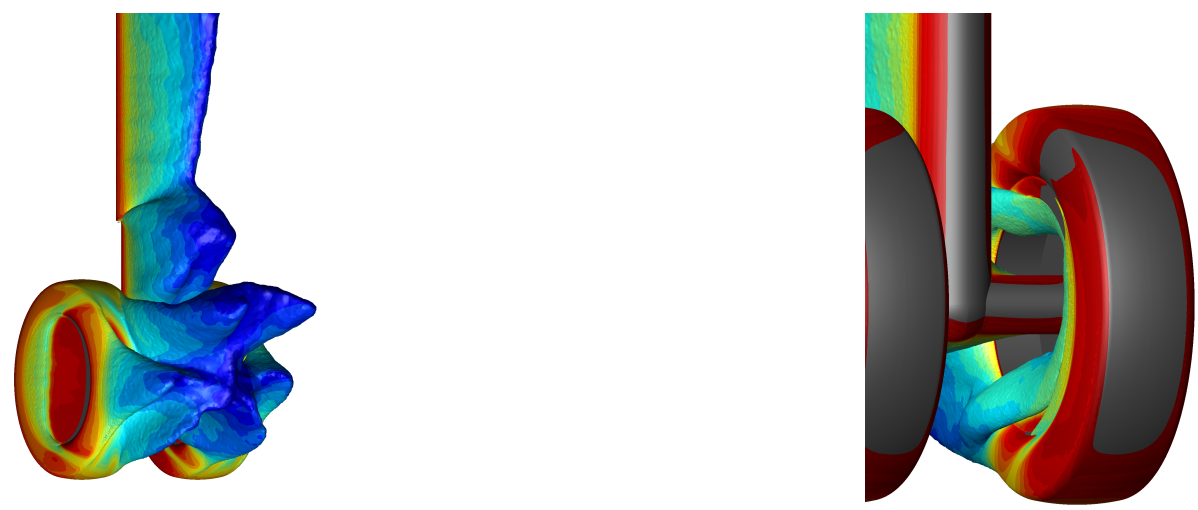

Figure 25: Total pressure iso-surface $\left(P_{t}=P_{\infty}\right)$ coloured by vorticity magnitude from 100 to $1.0 E+06 \mathrm{~s}^{-1}$

\section{Acoustic results}

In the present section, the main acoustic results will be discussed, covering an introduction to the experimental setup, the Ffowcs-Williams and Hawkings (FW-H) approach used, and the narrow band and integrated levels and directivity patterns.

\subsection{Experimental setup}

The aeroacoutic measurements were performed in ONERA's CEPRA19 anechoic wind tunnel, surrounded by an 11-meter quarter sphere chamber with its hard walls covered with foam, enabling an anechoicity of $99 \%$ for frequencies between $200 \mathrm{~Hz}$ and $80 \mathrm{kHz}$. The nozzle used has a diameter of $2 \mathrm{~m}$ and allows a maximum speed of 130 $\mathrm{m} / \mathrm{s}$.

As for the instrumentation, four sets of antennas were used. The first two ones were dedicated to far-field narrow band measurements in both flyover and sideline directions, this last one being placed at $56^{\circ}$ with respect to the flyover direction (see Figure 26 (middle and right) for the retained coordinate system). Each of the two antennas consists in 12 microphones evenly arranged in a 6-meter in radius arc, starting at $\theta=40^{\circ}$ in the upstream direction up to $\theta=150^{\circ}$ downstream of the landing gear. The other antennas were placed in flyover and "pure" sideline for beamforming analysis, but in the scope of CFD assessment, the focus will be made on the directivity antennas.

Microphone signals are corrected in order to take into account the background noise, the atmospheric absorption and refraction of the waves travelling through the shear layer generated by CEPRA19 inlet, obtaining the equivalent location of the virtual microphones placed in a uniform mean flow. 


\subsection{Numerical setup}

During the CFD computation (see §3), the unsteady pressure at the nodes of the surface grid has been recorded with a sampling frequency of $f_{s}=100 \mathrm{kHz}$.

The recorded data is used as an input for ONERA's in-house Ffowcs-Williams and Hawkings (FW-H) code KIM [21]. The code can deal both with solid surfaces and porous surfaces, but for the present study, only the solid surface formulation has been retained. The reasons for using only the solid surface integration are twofold. In first place, due to the low Mach number of the simulation, the quadripolar sources can be considered to be negligible compared to the dipolar terms at the surface of the landing gear. Secondly, in the different landing gear noise computations that can be found on literature, comparisons between solid and porous surface formulations always show a greater precision of the first approach. Finally, the use of a porous surface formulation implies an extra cost, because, not only it dramatically increases the storage needs, but also the grid has to be constructed in order to support and accurately propagate this quadripolar terms downstream of the landing gear. It is considered by the authors that the porous formulation does not present any advantage for the landing gear noise prediction in the present case.
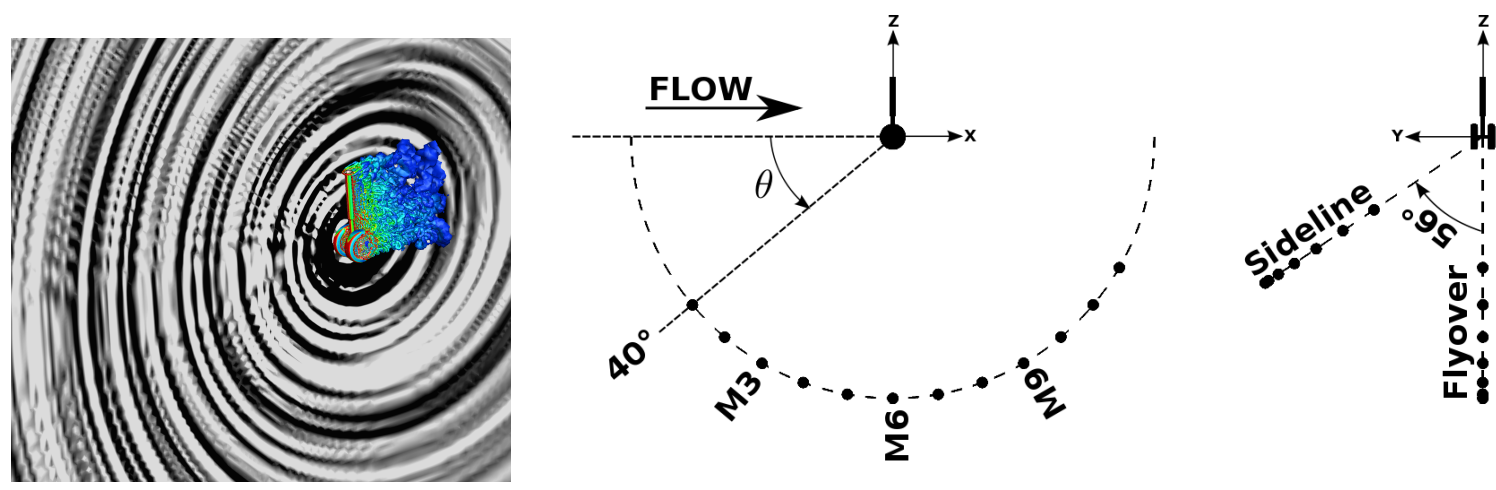

Figure 26: Instantaneous pressure fluctuation $\left(P^{\prime}= \pm 2 \mathrm{~Pa}\right)$ in the plane $Y / L=0.5$ from a FW-H computation on the solid surface of the landing gear (grey scale) and Q-criterion $\left(Q^{*}=52.9=Q \times M_{\infty}^{2}\right)$ coloured by the vorticity magnitude (left). Microphone location scheme in the flyover (middle) and sideline (right) directions

\subsection{Narrow band results}

The power spectral density (PSD) at the corrected location of the microphones is obtained based on the same signal treatment as for the unsteady pressure transducers, see $\$ 4.2$. The results for three selected microphones in the flyover and sideline arcs are presented in Figures 27 and 28, respectively.

Firstly, in Figures 27 and 28, there is an underestimation of the predicted levels in the low frequency range ( $f<$ $800 \mathrm{~Hz}$ ) for the upstream locations, on the shape of a $500 \mathrm{~Hz}$ tone, that tends to disappear when moving downstream. Secondly, the middle and high frequency range agrees very well with the measurements up to frequencies as high as $10 \mathrm{kHz}$ for most of the microphones. Finally, the tone observed at $1.5 \mathrm{kHz}$ in sideline microphones spectra during CEPRA19 experiments that corresponds to the one registered in the skin with the unsteady pressure measurements (see Figure 12 (top left)) and studied by D. Casalino [20] is well recovered. Nevertheless, in the upstream direction, the level of this tone is overestimated, with an almost perfect agreement in pure sideline $\left(\theta=90^{\circ}\right)$ and a suppression of the tone downstream of the landing gear.

Interestingly, the agreement with measurements in terms of frequency band, is quite different between the acoustic spectra and the wall pressure spectra (see Figures 10 and 12). The global trend is a shift towards higher frequencies for the acoustic spectra with respect to the wall pressure one. Two comment are necessary. On one hand, wall pressure spectra correspond to a rather local information of the flow whereas acoustic spectra are calculated from a surface integration that takes into account the whole landing gear skin. On the other hand, there is no obvious relationship in terms of broadband frequency content between wall pressure spectra information and far-field acoustics. In the end, the difficulty to establish necessary and sufficient criteria in the simulation to target an acoustic frequency band in far-field arises. The acoustic criteria on the grid cell size around the landing gear are necessary to ensure the acoustic 
propagation in near-field, but broadband noise in far-field is rather controlled by the accuracy of the flow simulation. On this point, the computational strategy based on the ZDES and mesh refinement for the attached boundary layer and high curvature areas seems successful. A longer time signal could improve the prediction of the low frequency range noise.

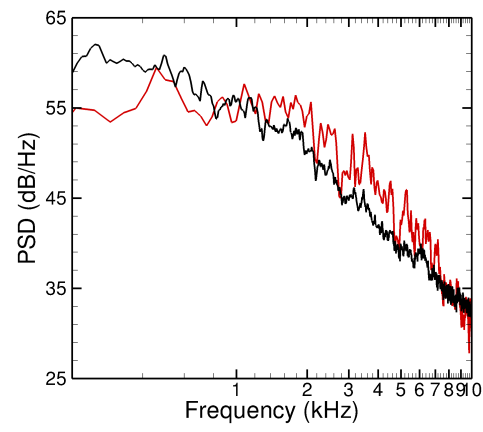

(a) Flyover 3

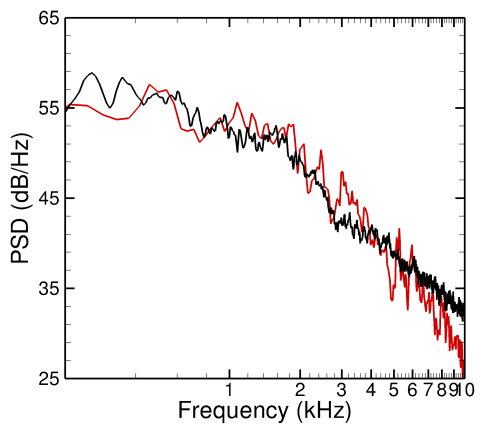

(b) Flyover 6

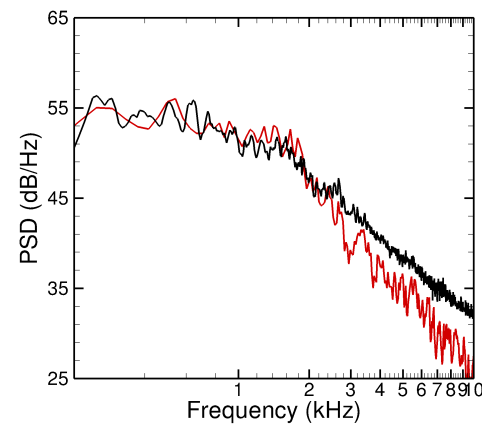

(c) Flyover 9

Figure 27: Power spectral density (PSD) of the microphones Flyover 3 placed at $\theta=60^{\circ}$ (a), Flyover 6 at $\theta=90^{\circ}$ (b) and Flyover 9 at $\theta=120^{\circ}$ (c). The red line (-) represents the numerical results and the black line $(-)$ corresponds to the experimental results obtained in CEPRA19

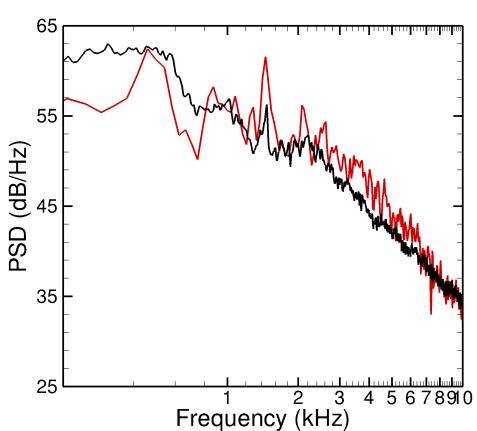

(a) Sideline 3

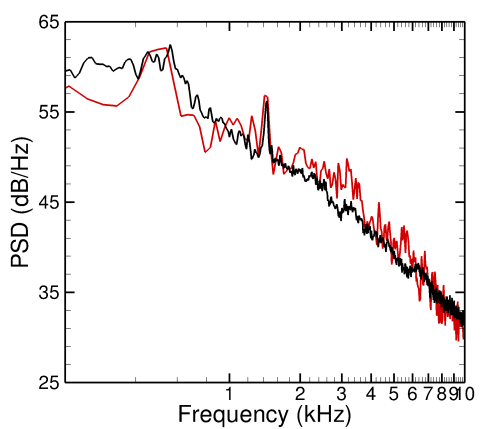

(b) Sideline 6

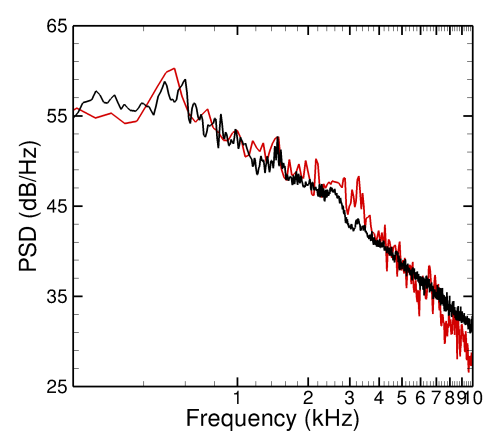

(c) Sideline 9

Figure 28: Power spectral density (PSD) of the microphones Sideline 3 placed at $\theta=60^{\circ}$ (a), Sideline 6 at $\theta=90^{\circ}$ (b) and Sideline 9 at $\theta=120^{\circ}$ (c). The red line $(-)$ represents the numerical results and the black line $(-)$ corresponds to the experimental results obtained in CEPRA19

\subsection{Directivity}

Finally, the directivity of the emitted noise has been addressed through the Overall Sound Pressure Level (OASPL), calculated by integration of the Power spectral density (PSD) of the different microphones in the $200 \mathrm{~Hz}$ to $10 \mathrm{kHz}$ frequency range. The results are presented both for the flyover and sideline arc in Figure 29.

In both directions, the agreement with the experimental results is very close, with only a small overestimation of the levels (about 1 to $1.5 \mathrm{~dB}$ ) in the downstream part of the sideline arc. At the same time, this location presented the minimum signal to noise ratio during the experimental measurements, possibly explaining this discrepancy. In terms of directivity, the landing gear has a privileged propagation direction toward the upstream, with higher levels in sideline than in flyover. 


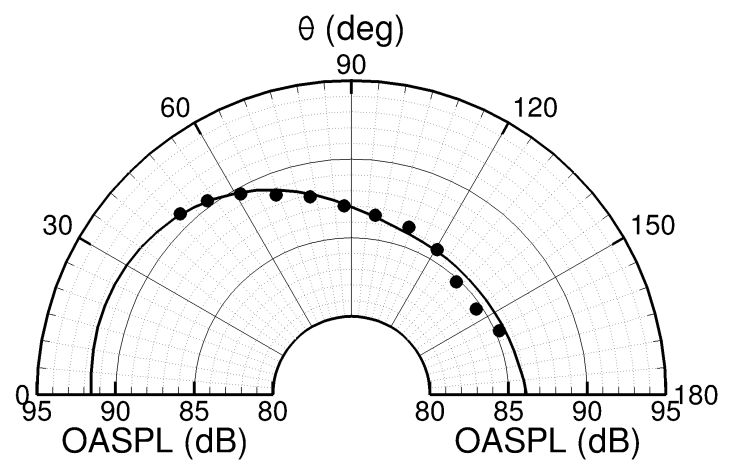

(a) Flyover

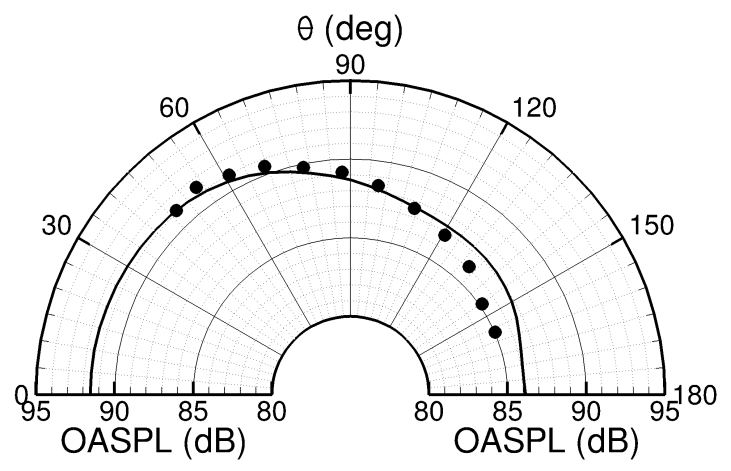

(b) Sideline

Figure 29: Overall Sound Pressure Level (OASPL) calculated by integration of the PSDs in the $200 \mathrm{~Hz}-10 \mathrm{kHz}$ frequency range. Flyover (a) and sideline arc (b). The solid line $(-)$ represents the numerical results while the dots $(\bullet)$ correspond to the experimental results obtained at CEPRA19

This is confirmed not only in Figure 29 where only the directivity in the flyover and sideline directions are shown but also in Figure 30, where, the OASPL on a 6 meter in radius half sphere are presented. This array has an azimuthal and elevation resolution of $5^{\circ}$, containing about 1300 virtual microphones. Two particular points are clearly visible on that figure: the high levels obtained in the upstream direction, specially for high elevations $\left(\beta>45^{\circ}\right)$ while there is an intense shadow zone in the downstream direction $\left(\alpha=180^{\circ}\right)$, with levels being about $6 \mathrm{~dB}$ lower than the upstream direction, for almost any elevation angle $\phi$.
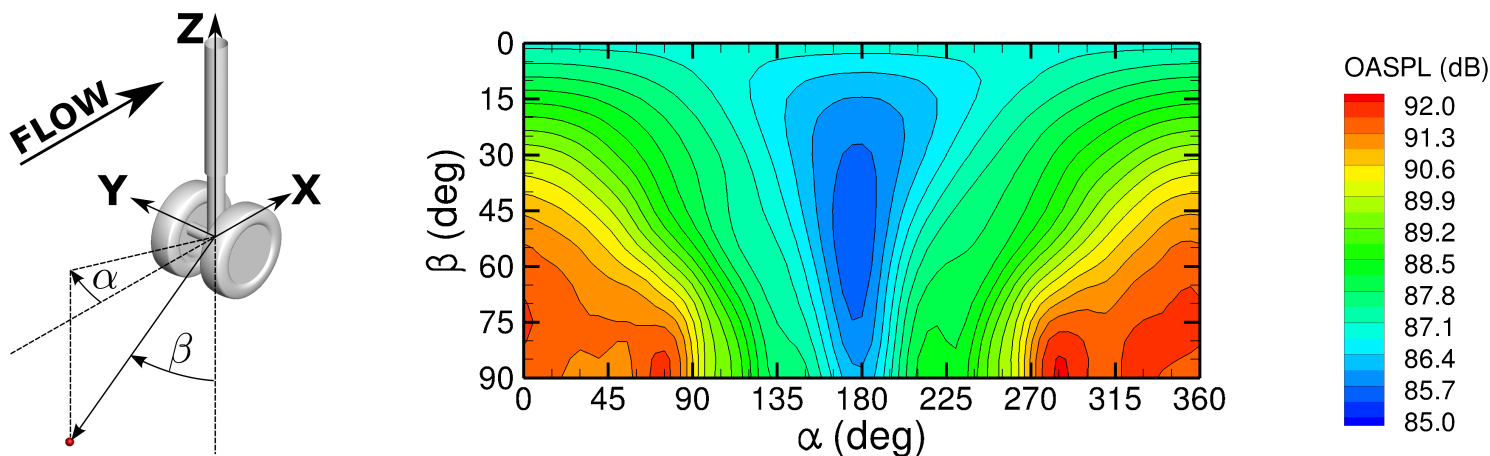

Figure 30: OASPL in a $6 \mathrm{~m}$ radius sphere

\section{Conclusions}

An aeroacoustic computation of the LAGOON two wheel simplified nose landing gear has been successfully performed using an unstructured grid and a Zonal Detached Eddy Simulation (ZDES) model implemented in the Navier-Stokes solver CHARME of ONERA CEDRE code.

A detailed description of the mesh generation process has been provided, covering a detailed insight of the different cell sizes used both at the skin and in the volume. In particular, mesh efforts have been made on the high curvature areas, that were specially finally meshed in order to accurately locate the flow detachments. On the other hand, during the mesh generation process special attention has been paid to avoiding small volume cells, of low quality, that greatly penalize the CFL number and hence the total CPU cost of a given simulation. 
In terms of turbulence model, the Zonal Detached Eddy Simulation (ZDES) has been retained as it offers a good compromise between cost and performance, thanks to the use of accurate and inexpensive RANS models for solving Spalart-Allmaras RANS model has been used, proving that is capable of accurately reproducing the evolution of the turbulent boundary layers over the landing gear despite not having considered the laminar to turbulent boundary layer forcing used on the experiments. Furthermore, it enables a significant cost reduction when compared to the two-equation k- $\omega$ SST turbulence model. of the computed flow field with the experiments in terms of time-averaged results and spectral content, it proves that the computation based on unstructured grids and Navier-Stokes equations based solvers can produce high quality CFD results at a moderate cost while, at the same time, accurately resolving the attached boundary layers. Finally, the farfield acoustics computed by integration of the wall pressure on the landing gear skin according to the FW-H equation, showed a very close agreement with experiments in terms of integrated levels and spectral content. It confirms the relevancy of the CFD approach presented in this study for the prediction of landing gear noise and encourages its use for predicting flow and noise of more complex landing gear geometries, as shown by the authors in a recent study Ref. [22].

\section{Acknowledgements}

Authors would like to thanks ONERA's Fluid Mechanics and Energetics scientific branch for founding this study. They would like also to thank Airbus for founding the experimental campaigns as well as for freely providing the database obtained in the framework of the American Institute of Aeronautics and Astronautics (AIAA) Benchmark on Airframe Noise Computations (BANC) category 5.

\section{References}

1] J. F. Piet, R. Davy, G. Elias, H. Siller, L. Chow, C. Seror, F. Laporte, Flight test investigation of add-on treatments to reduce aircraft airframe noise, in: 11th AIAA/CEAS Aeroacoustics Conference, May 23-25, 2005, Monterey, California, USA, no. AIAA paper 2005-3007, 2005.

[2] W. Liu, J. W. Kim, X. Zhang, D. Angland, B. Caruelle, Landing-gear noise prediction using high-order finite difference schemes, Journal of Sound and Vibration 332 (14) (2013) 3517-3534.

[3] P. R. Spalart, M. L. Shur, M. K. Strelets, A. K. Travin, Initial noise predictions for rudimentary landing gear, Journal of Sound and Vibration 330 (17) (2011) 4180-4195.

[4] R. B. Langtry, J. V. Larssen, C. M. Winkler, A. J. Dorgan, M. Mani, DDES and acoustic prediction of rudimentary landing gear experiment using unstructured finite volume methods, Flow, Turbulence and Combustion 91 (3) (2013) 717-745.

[5] J.-C. Giret, Simulations aux grandes échelles des écoulements instationnaires turbulents autour des trains d'atterrissage pour la prédiction du bruit aérodynamique, Ph.D. thesis, thése de doctorat dirige par Jouhaud, Jean-Christophe et Stéphane, Moreau Dynamique des fluides Toulouse, INPT 2014 (2014).

[6] P. R. Spalart, S. Deck, M. L. Shur, K. D. Squires, M. K. Strelets, A. Travin, A new version of detached-eddy simulation, resistant to ambiguous grid densities, Theoretical and Computational Fluid Dynamics 20 (3) (2006) 181-195.

[7] S. Deck, Recent improvements in the zonal detached eddy simulation (ZDES) formulation, Theoretical and Computational Fluid Dynamics 26 (6) (2012) 523-550.

[8] D. Casalino, A. F. P. Ribeiro, E. Fares, S. Nölting, Lattice-Boltzmann Aeroacoustic Analysis of the LAGOON Landing-Gear Configuration, AIAA Journal 52 (2014) 1232-1248.

[9] M. Murayama, Y. Yokokawa, K. Yamamoto, T. Hirai, Computational study of low-noise fairings around tire-axle region of a two-wheel main landing gear, Computers and Fluids 85 (2013) 114-124, international Workshop on Future of CFD and Aerospace Sciences.

[10] E. Manoha, J. Bulté, B. Caruelle, LAGOON: An experimental database for the validation of CFD/CAA methods for landing gear noise prediction, in: 14th AIAA/CEAS Aeroacoustics Conference, May 5-7, 2008, Vancouver, British Columbia, Canada, no. AIAA paper 2008$2816,2008$.

[11] E. Manoha, J. Bulté, V. Ciobaca, B. Caruelle, LAGOON: Further analysis of aerodynamic experiments and early aeroacoustics results, in: 15th AIAA/CEAS Aeroacoustics Conference, May 11-13, 2009, Miami, Florida, USA, no. AIAA paper 2009-3277, 2009.

[12] F. de la Puente, L. Sanders, F. Vuillot, On LAGOON nose landing gear CFD-CAA computation over unstructured mesh using a ZDES approach, in: 20th AIAA/CEAS Aeroacoustics Conference, June 16-20, 2014, Atlanta, Georgia, USA, no. AIAA paper $2014-2763,2014$.

[13] A. Refloch, B. Courbet, A. Murrone, P. Villedieu, C. Laurent, P. Gilbank, J. Troyes, L. Tessé, G. Chaineray, J. Dargaud, E. Quémerais, F. Vuillot, CEDRE software, in: CFD Platforms and coupling, Aerospace Lab, no. Issue 2, 2011.

[14] N. Chauvet, S. Deck, L. Jacquin, Zonal detached eddy simulation of a controlled propulsive jet, AIAA Journal 45 (10) (2007) $2458-2473$.

[15] P. R. Spalart, S. R. Allmaras, A one-equation turbulence model for aerodynamic flows, La Recherche aerospatiale (1) (1994) 5-21.

500 [16] E. F. Toro, M. Spruce, W. Speares, Restoration of the contact surface in the HLL-Riemann solver, Shock Waves 4 (1) (1994) $25-34$. 
[17] E. Manoha, B. Caruelle, LAGOON simplified (2-wheel) nose landing gear Benchmark for Airframe Noise Computations problem statement, no. Document R19 version 2, 2014

[18] C. Mockett, T. Knacke, F. Thiele, Detection of initial transient and estimation of statistical error in time-resolved turbulent flow data, in: Proceedings of the 8th International Symposium on Engineering Turbulence Modelling and Measurements (ETMM8), June 9-11, 2010, Marseille, France.

[19] E. Manoha, B. Caruelle, Summary of the LAGOON solutions from the Benchmark problems for Airframe Noise Computations-iii Workshop, in: 21st AIAA/CEAS Aeroacoustics Conference, June 22-26, 2015, Dallas, Texas, USA, no. AIAA paper 2015-2846, 2015.

[20] D. Casalino, A. F. Ribeiro, E. Fares, Facing rim cavities fluctuation modes, Journal of Sound and Vibration 333 (13) (2014) 2812-2830.

[21] J. Prieur, G. Rahier, Aeroacoustic integral methods, formulation and efficient numerical implementation, Aerospace Science and Technology 5 (7) (2001) 457-468.

[22] F. D. L. Puente, L. Sanders, F. Vuillot, E. Manoha, Nose landing gear flow and noise predictions on unstructured grid using a cell-centered navier-stokes code, in: 21st AIAA/CEAS Aeroacoustics Conference, June 22-26, 2011, Dallas, Texas, USA, no. AIAA paper 2015-3256, 2015. 